San Jose State University

SJSU ScholarWorks

Master's Theses

Master's Theses and Graduate Research

Spring 2013

\title{
An Ecological Assessment of Insect Diversity at Organic Central Coast Vegetable Farms on Two Spatial Scales
}

Emily Musgrave

San Jose State University

Follow this and additional works at: https://scholarworks.sjsu.edu/etd_theses

\section{Recommended Citation}

Musgrave, Emily, "An Ecological Assessment of Insect Diversity at Organic Central Coast Vegetable Farms on Two Spatial Scales" (2013). Master's Theses. 4298.

DOI: https://doi.org/10.31979/etd.yw3p-kgs5

https://scholarworks.sjsu.edu/etd_theses/4298

This Thesis is brought to you for free and open access by the Master's Theses and Graduate Research at SJSU ScholarWorks. It has been accepted for inclusion in Master's Theses by an authorized administrator of SJSU ScholarWorks. For more information, please contact scholarworks@sjsu.edu. 


\title{
AN ECOLOGICAL ASSESSMENT OF INSECT DIVERSITY AT ORGANIC
} CENTRAL COAST VEGETABLE FARMS ON TWO SPATIAL SCALES

\section{A Thesis}

Presented to

The Faculty of the Department of Environmental Studies

San Jose State University

\author{
In Partial Fulfillment \\ of the Requirements for the Degree \\ Master of Science
}

by

Emily A. Musgrave

May 2013 
(C) 2013

Emily A. Musgrave

ALL RIGHTS RESERVED 
The Designated Thesis Committee Approves the Thesis Titled

AN ECOLOGICAL ASSESSMENT OF INSECT DIVERSITY AT ORGANIC CENTRAL COAST VEGETABLE FARMS ON TWO SPATIAL SCALES

by

Emily A. Musgrave

APPROVED FOR THE DEPARTMENT OF ENVIRONMENTAL STUDIES

SAN JOSÉ STATE UNIVERSITY

May 2013

Dr. Rachel O’Malley

Dr. Lynne Trulio

Dr. Deborah Letourneau
Department of Environmental Studies

Department of Environmental Studies

Department of Environmental Studies

University of California, Santa Cruz 
ABSTRACT

\title{
AN ECOLOGICAL ASSESSMENT OF INSECT DIVERSITY AT ORGANIC CENTRAL COAST VEGETABLE FARMS ON TWO SPATIAL SCALES
}

\author{
by Emily A. Musgrave
}

Modern industrial agriculture is the principal cause of anthropogenic land use changes for terrestrial ecosystems. Approximately $40 \%$ of the planet's land surface, or half of the habitable area, is now composed of agricultural landscapes. The simplification and industrialization of agriculture are the biggest drivers of global biodiversity loss, especially on Californian’s Central Coast. Diversified organic agriculture, however, may offer some refuge for non-crop species. In this study we analyzed insect and plant biodiversity on and adjacent to organic vegetable farms on the Central Coast of California at two spatial scales, the landscape-scale and a smaller within-farm scale. At the landscape-scale, insect data were collected using malaise traps across 35 organic farms in 2005 and 2006, and vegetation diversity was assessed using $0.5 \mathrm{~km}$-radius circular plots. At the smaller farm-scale, insect biodiversity was assessed using 4.5 cm-radius pan traps to collect insects in a single heterogeneous organic farm in 2012, and vegetation was assessed in 1.5 m-radius circular plots. Non-crop vegetation biodiversity was associated with insect biodiversity at both scales, but landscape-scale results showed greater temporal and spatial variation than farm-scale results. Overall, the diverse farm systems enhanced the biological diversity and productivity of the agricultural landscape. 


\section{ACKNOWLEDGEMENTS}

I would not have been able to complete this thesis without the support and guidance of my advisers, peers, friends and family, and I will never forget their unwavering words of encouragement and motivation throughout this endeavor. I would like to begin by thanking my thesis committee members, Dr. Rachel O’Malley, Dr. Deborah Letourneau and Dr. Lynne Trulio. Their constant optimism and confidence helped me persevere throughout this process. The knowledge they imparted to me and the wisdom I have gained working with them will stay with me throughout my life.

I would also like to thank the College of Social Sciences at San Jose State University for providing me with financial support that allowed me to purchase the equipment for this study. I'm also grateful to the Department of Environmental Studies for allowing me to use their field equipment.

This study would not have been possible without the cooperation and help of Thomas Broz, who allowed me to use his farm for my study and was supportive and helpful throughout the data collection process. I am also very grateful to the group of undergraduate students in the Sustainable Agriculture Class who helped me collect my field data.

Lastly, I would like to thank my family and friends for providing the intellectual and emotional support I needed to accomplish this monumental goal. My parents’ steadfast support has allowed me to pursue my educational goals, and their continued guidance and help—emotionally, intellectually and financially_-have been the stepping stones for my success in the Master’s program at San Jose State University. I will be 
forever grateful to them. I'm thankful for my sister and brother-in-law, for their guidance, expertise, and emotional support throughout the thesis-writing process. I am also very grateful to my fiancée for his unfaltering support and dedication throughout my career at San Jose State University. I would like to thank Miranda Melen, a friend and peer who has been a constant source of knowledge and encouragement during my time in this program. Lastly, I am very thankful to have been able to participate in the Environmental Studies Master’s Program at San Jose State University. It has enriched and fulfilled my life in more ways than I thought possible, and has given me the knowledge and excitement to continue in this field. 


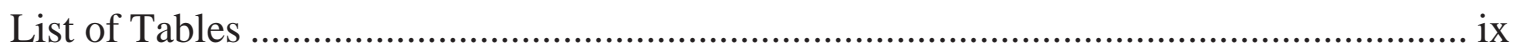

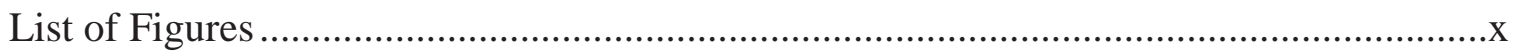

Chapter

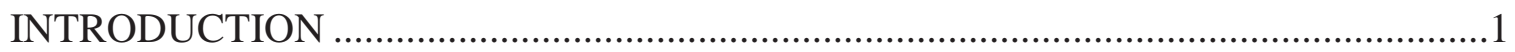

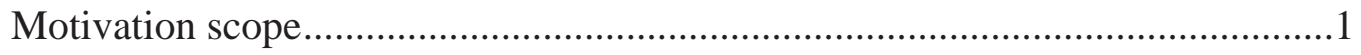

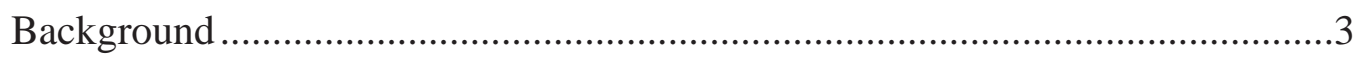

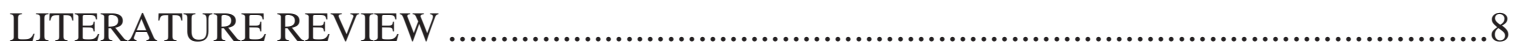

Biodiversity of agricultural systems ...............................................................

Global environmental footprint of modern agriculture........................................11

Agriculture as a driver of global biodiversity loss ................................................13

Natural enemies in agricultural systems ..........................................................14

Plant diversity and pests....................................................................................17

Importance of Diptera (flies) in agroecosystems .................................................18

Multi-functional aspects of agricultural production ............................................19

Agriculture in the United States.............................................................................23

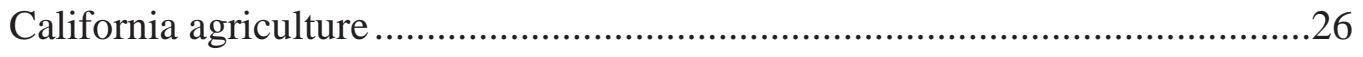

Agriculture on the Central Coast ..........................................................................27

California Central Coast ecosystems ……………………………………….....29

The agricultural crisis: The need for an interdisciplinary approach .....................34

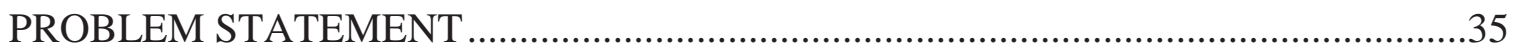




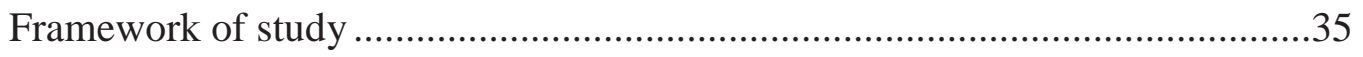

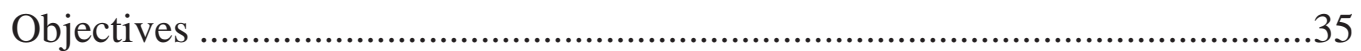

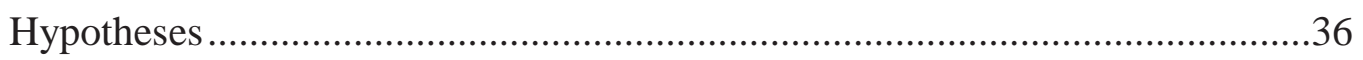

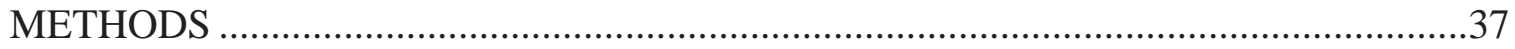

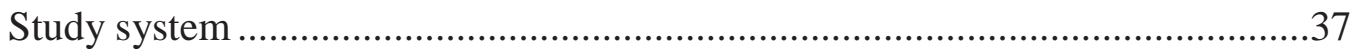

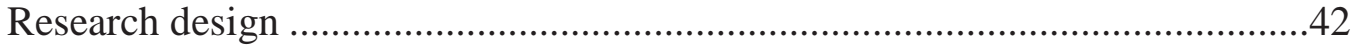

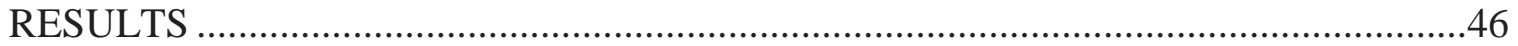

H1a,b landscape-scale biodiversity ........................................................46

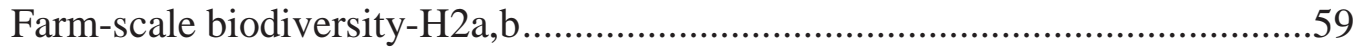

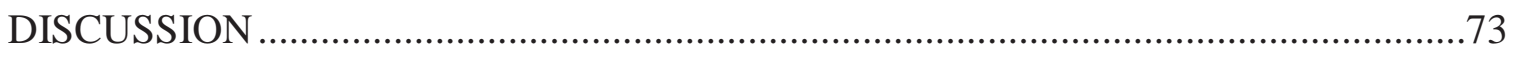

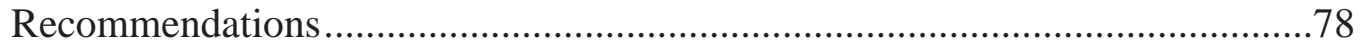

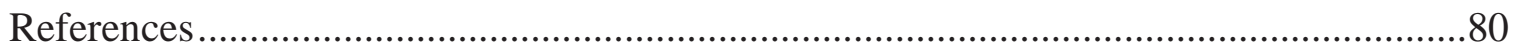




\section{LIST OF TABLES}

Page

1. Endemic Species of the Central Coast ..........................................................30

2. Special Status Invertebrates of the Central Coast ............................................31

3. Common Insect Morphospecies at the Landscape-scale .................................49

4. Overview of Landscape-scale Results ........................................................50

5. Common Insect Morphospecies from Live Earth Farm .................................62

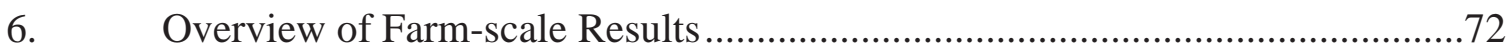




\section{LIST OF FIGURES}

Page

1. Map of Study Locations-Created by Sara Bothwell Allen ...............................38

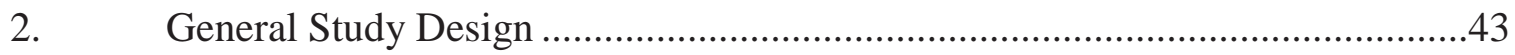

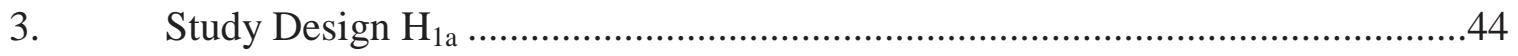

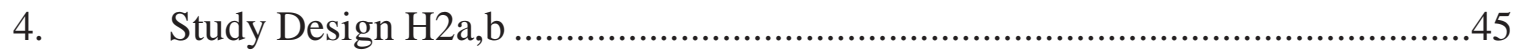

5. Principle Component 1 versus Mean Hymenoptera Abundance Spring, Summer and Fall 2005 .....................................................................................52

6. Principle Component 1 versus Mean Hymenoptera Richness Spring and

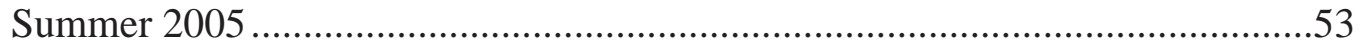

7. Principle Component 3 versus Hymenoptera Richness and Abundance Over All Sample Dates ..............................................................................55

8. Grasslands versus Hymenoptera Richness Spring 2005 ..................................56

9. Non-Crop Species Richness versus Hymenoptera Abundance Over All Samples Dates from 2005.

10. Non-Crop Species Richness versus Hymenoptera Species Richness

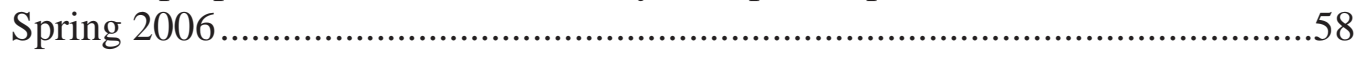

11. Principle Component 1 versus Insect Abundance ..........................................64

12. Principle Component 1 versus Insect Species Richness ..................................65

13. Principle Component 2 versus Insect Abundance ........................................67

14. Principle Component 2 versus Insect Species Richness ...................................68

15. Non-crop Cover versus Insect Abundance .................................................70

16. Non-crop Cover versus Insect Species Richness .........................................71 


\section{Introduction}

\section{Motivation scope}

Modern industrial agriculture is the most widespread cause of anthropogenic land use changes on terrestrial ecosystems (Kim et al. 2006). Agricultural intensification across the world has permanently modified our landscapes and changed the way we must think about and manage these lands. Approximately 40\% of the planet's land surface, or around half the habitable area, comprises agricultural landscapes (DeFries et al. 2004; Donald and Evans 2006). Croplands and pastures now rival forest cover to occupy the greatest extent of the world's terrestrial landscape (Foley et al. 2005). The industrialization of agriculture and the increasing amount of landscape devoted to its production are two of the biggest drivers of biodiversity loss. Conservation biologists regard the distribution of agricultural land, not the distribution of people, as the number one indicator of threats to species biodiversity (Donald and Evans 2006). With worldwide agricultural production set to double by 2050 (Butler et al. 2007), sustainable agro-ecological methods must be implemented to reverse the trend of increasing biodiversity loss and to create healthy agroecosystems.

Intensive agricultural production is driving the destruction of the planet's greatest biodiversity hotspots, tropical rainforests. According to Perfecto and Vandermeer (2008), approximately 70\% of land in tropical regions is a mixture of agricultural lands, pastures, and managed landscapes. Biodiversity loss in the pristine tropical forests is an important issue getting worldwide media attention; however, wildlife relying on 
agricultural landscapes and farms are an important concern receiving much less notice around the world.

Worldwide agricultural intensification is a serious global issue, causing severe degradation to ecosystems and driving biodiversity loss worldwide. With a growing world population and a global food supply projected to double by the year 2050, the need for sustainable agriculture as an antidote to these problems has never been greater (Tilman 1999). As defined by Lowrance et al. (1986), “sustainable agriculture” has four hierarchical steps, which include agronomic sustainability, microeconomic sustainability, macroeconomic sustainability, and ecological sustainability. Agroeconomic stability means that the land can sustain its productivity over time, while ecological sustainability refers to maintaining the biodiversity and ecosystem functioning of non-agricultural plants and animals in the landscape. Microeconomic stability refers to the farm as a business and its role as a form of financial income, whereas macroeconomic stability refers to things outside the farm-scale control, such as state and national farm policies, interest rates, and other fiscal policies.

Simply stated, "sustainable agriculture" refers to agricultural practices that meet our society's current and future needs for food and fiber, while maximizing the benefits of agriculture and minimizing, to the best degree possible, negative environmental and social impacts (Tilman et al. 2002). A doubling of global food production under current agriculture practices would be disastrous for our planet's agroecosystems and the services they provide. According to Altieri (2002), “agroecosystems” are communities of plants, 
animals, and microorganisms that live and interact together in ecosystems modified by humans to produce essential commodities such as food, fiber, and fuel.

The implementation of sustainable agroecological practices is a potential solution that will reduce detrimental environmental impacts while preserving the vital services providing food staples to people around the world. Managing agricultural landscapes based on agroecological principles will help protect wildlife and create healthy ecosystems that can be sustained for future generations. Such agroecological principles include using beneficial processes that naturally occur on farms, mimicking the ecosystem functioning of natural environments, and maintaining a diversity of crops and vegetation throughout the farm and surrounding landscapes (Altieri 2002). By implementing sustainable agroecological principles, biologists believe we have the capability to reverse the trend of biodiversity loss as well as maintain the ecosystem goods and services sustaining the livelihoods of people around the world.

\section{Background}

Agriculture, managed forests, and human settlements comprise 95\% of terrestrial landscapes, providing habitats for the majority of the world's biodiversity (Pimentel et al. 1992). The growing demand for agriculture and its subsequent intensification is renowned as the greatest threat to our planet's wildlife. Consequently, any attempt to address the loss of biodiversity around the planet must focus on conservation efforts in these managed landscapes, and special focus must be placed on maintaining biodiversity in these ecosystems. Barlow et al. (2010) point out that successful efforts to conserve the world's declining biodiversity will depend on how we manage these altered landscapes. 
Similarly, Donald and Evans (2006) note sustainable agroecological practices can help improve species diversity and lead to healthy ecosystems by reversing the damages of industrial agricultural practices.

With the global food demand projected to double due to a predicted 50\% increase in the world population by 2050, the push to convert more of the world's natural ecosystems into managed agricultural landscapes is strong. The shifting of unmanaged ecosystems to agricultural land continues to be a leading driver of global habitat destruction. Tilman (2001) predicted that by 2050, the amount of global agricultural land will be $18 \%$ larger than current levels. Tilman also points out that the majority of the increased agricultural lands are predicted to occur in Latin America and sub-Saharan and central Africa. These scenarios would be catastrophic for global biodiversity and the overall health of our planet's ecosystems. This expansive increase in agricultural land could lead to the destruction of approximately $33 \%$ of the planet's remaining tropical and temperate forests, savannas, and grasslands. Habitat loss and species extinctions would be pervasive, and there would be a global loss in carbon sinks as the world's forests continue to diminish. Other ecosystem goods and services, such as potable water, food, timber and non-timber products, and recreation, would also be lost with the conversion of these natural lands to managed agricultural landscapes (Tilman 2001).

Agriculture creates patchworks of highly fragmented environments posing a threat to wildlife, especially for animals requiring large intact habitats to survive. This widespread habitat fragmentation has resulted in the loss of wildlife species around the world (Hilty et al. 2006). Green et al. (2005) noted the way we manage our farmland will 
have the greatest impact on the planet's wildlife. These authors showed that converting unmanaged land to farms as well as intensifying agricultural techniques on existing farmlands poses the greatest threat to survival of threatened bird species. Habitat destruction and biodiversity loss also negatively affect agricultural cultivation, as the services of many pollinators, including bees, are compromised with agricultural expansion and intensification. Thus, current unsustainable agricultural practices provide short-term increases in food production at the cost of permanently damaging future ecosystem services, including services essential to agricultural production (Foley et al. 2005).

In 1992, Pimentel et al. showed that preserving species biodiversity in managed environments is linked to maintaining productive agricultural and forestry landscapes. They pointed out high agricultural yields and healthy human populations have an intrinsic association with the diversity of natural flora and fauna. In another study, Thrupp (2000) argued agricultural biodiversity on farms is necessary to ensure food security. Agrobiodiversity also provides other important ecosystem goods and services including maintaining habitats for pollinators and beneficial insects and reducing soil water runoff (Thrupp 2000).

As worldwide agricultural intensification has increased, there has been a shift from traditional diverse farming systems to large tracts of monocultures. With the technological advancements of modern agricultural and conventional systems on the rise, biologically diverse farming systems worldwide have been declining. In the developing world, traditional multi-cropping and subsistence agriculture have suffered due to the top- 
down technology approach of agriculture. This negative trend can be attributed to the biases of "modern scientific knowledge" as well as to the neglect of the traditional knowledge of rural farming communities and their exclusion from participation in new developing farming practices. New technological practices are also exclusionary based on financial resources, as poor farmers with small plots of land benefit very little, while farmers with larger areas of land and more financial resources are the only people benefiting from this top-down approach of agricultural reform. For example, in Latin America, $61 \%$ of the rural population is considered poor, and in Africa the majority of the farmers are peasants who continue to practice subsistence agriculture in rural valleys and hills scattered throughout the countryside (Altieri 2002). Tropical agroforestry systems, traditional home gardens, and farming practices mimicking and incorporating the biodiversity of the natural environment into their farming systems are decreasing. This trend has transformed vast areas of once richly diverse agricultural landscapes into large tracts of homogenous landscapes threatening species biodiversity throughout the planet (Thrupp 2000). For example, many of the world's major crops, such as corn, wheat, rice, soybeans, sugar cane, and a majority of others, are cultivated as monocultures (Tilman 1999).

Agricultural intensification and the widespread adaptation of external outputs, such as chemical pesticides and fertilizers, have greatly diminished the biodiversity of agroecosytems. The central ecosystem functions of most of our agricultural landscapes have been radically altered due to past and present anthropogenic forces and have created new ecological communities completely different from their original ecological systems 
(Gardner et al. 2010). The world's agricultural systems provide essential ecosystem goods and services to local people as well as to the global community. The international market for agricultural ecosystem goods and services continues to skyrocket, which has resulted in accelerated intensification processes continuing to threaten the world's biodiversity. One example of an area extremely vulnerable to the international market is tropical rainforests. Rainforest ecosystems have been transformed into large areas of agricultural lands through increased economic development, increased demand for agricultural exports on the international market, and government policies that have encouraged clearing the land for agricultural purposes (Barona et al. 2010). Thus, the economies of these tropical forest nations are extremely susceptible to national and international market pressures because of the global demand for the ecosystem goods and services the forests produce (Nepstad et al. 2006). 


\section{Literature Review}

\section{Biodiversity of agricultural systems}

The majority of the world's biodiversity occurs in human-managed landscapes, including agricultural and forest ecosystems. These managed ecosystems cover a vast amount of Earth’s environment and compose approximately 95\% of terrestrial landscapes. The term “biodiversity” encompasses all species of plants, animals, and microorganisms living together in a particular ecosystem (Altieri 1999). When referring to biodiversity, the trend is to think about large flowering plants and charismatic megafauna, such as majestic giant redwoods or mischievous monkeys in tropical forest regions. However, the diversity of smaller plants and animals is a vital part of the functionality of our world's ecosystems. For example, $90 \%$ of the world's species are arthropods - invertebrates with exoskeletons - and both natural and managed croplands and forests contain a rich diversity of these species.

Arthropods contain a large amount of the planet's biomass, and studies have shown that in temperate and tropical agroecosystems, the number of different arthropod species varies between 262 and 1000 animals per hectare. Pimentel et al. (1992) demonstrated that arthropod diversity differs comparatively little between a managed corn agroecosystem and a natural unmanaged forest. In a study by Pimentel et al. (2005) comparing organic and conventional farms in Pennsylvania, the biodiversity of microarthropods and earthworms on organic farms was found to be twice that of those on conventional farms. Earthworms and other insects play an important role in the complex 
dynamics of a healthy ecosystem because the holes they create in the soil serve as a mode of water percolation, and consequently decrease runoff (Pimentel et al. 2005).

Agroecosystems also act as sanctuaries for many species and provide a refuge for wildlife increasingly losing their habitats through fragmentation and human encroachment (Kim et al. 2006). According to a study conducted by Chapin et al. (2000), projections indicate that by 2100 the leading cause of global biodiversity loss will be anthropogenic land-use change, driven extensively by the creation of industrialized agricultural lands. Habitat destruction from agricultural conversion and intensification poses great risks to species diversity. Thus, land-use decisions must find equilibrium between the intrinsically related facets of providing for human livelihoods while maintaining healthy ecosystems to sustain future generations (DeFries et al. 2004).

Agricultural research has demonstrated that in many cases the relationship between biodiversity and crop productivity is positive. For example, a 7-year experiment at the Minnesota Cedar Creek farm showed grassland plots with the greatest diversity resulted in greater yields than the monocultures (Robertson et al. 2004). In another study at the Kellogg Biological station in Michigan, researchers conducted a 10-year experiment on cropping systems and their relationship to greenhouse gas emissions. Robertson et al.’s (2004) results showed diverse polyculture cropping systems could serve as a tool to mitigate greenhouse gas production in agriculture. Other studies have shown complex agroecosystems with high levels of biodiversity create healthy ecosystems sustainable for longer periods of time than simple agroecosystems (Andow 
1991, Letourneau et al. 2011). These multi-species ecosystems are also more reliable in terms of crop production (Altieri 2002).

Sustainable agro-ecological techniques, such as low or no-till practices and use of cover crops and animal manure, increase the amount of organic matter in the soil and fertility in the ecosystem as compared to conventional intensive agriculture (Matson et al. 1997). Soil organic matter provides essential nutrients and can also increase biodiversity of soil microorganisms. Healthy soil creates healthy ecosystems and provides essential ecological components to the environment, including protecting crops from pests (Pimentel et al. 2005). Matson et al. (1997) also concluded such sustainable practices may provide an avenue for reversing the trend of soils as carbon sources and turn them into sinks for the potent greenhouse gas carbon dioxide.

Biodiversity conservation efforts continue to focus on remarkable species facing extinction, such as polar bears and tigers. Although these species are greatly deserving of protection and conservation measures must be implemented to thwart their extirpation, small organisms, such as invertebrates and microbes, also deserve protection. Many of these animals have very specialized niches and thus are more vulnerable to extinction when part of their habitat is removed or destroyed. Healthy levels of arthropods, microbes, and other small organisms in agricultural and other managed settings provide an array of diverse organisms that create stable ecosystems (Pimentel et al 1992). Although the concern about biodiversity loss in the tropics is merited and deserves worldwide attention, biodiversity in temperate regions is also of importance and deserves equal concern. According to Pimentel et al. (1992), some temperate ecosystems support 
more arthropods than tropical ecosystems. Thus, the case has been made that although the tropics are a large piece of the global biodiversity crisis, much conservation work is still needed in industrialized temperate zones, especially the agricultural sectors.

\section{Global environmental footprint of modern agriculture}

Technological advances of modern agriculture have increased global food supplies and reduced malnutrition, but this has come at the expense of vast environmental degradation. The ecological damage of intensive agricultural systems can be seen at the local, regional, and global levels. Locally, intensive agriculture degrades soil quality, increases erosion, reduces biodiversity, creates habitat destruction, and drives deforestation, while at the regional level it creates groundwater pollution and eutrophication of aquatic ecosystems. At the global level, it creates air pollution and is a contributor to climate change (Matson et al. 1997). Worldwide intensification of agricultural production has grabbed the attention of conservation biologists and scientists as it has transformed the landscape patterns of our natural ecosystems. The expansion of agricultural lands has resulted in the destruction of $70 \%$ of the world's grasslands, $50 \%$ of savannas, $45 \%$ of temperate deciduous forests, and 27\% of tropical forests (Matson et al. 1997). It has left us with vast areas of agricultural patchworks containing little species diversity. The heterogeneous landscapes supporting large amounts of biodiversity are becoming isolated fragments within the larger homogenous agricultural matrix. As global food production increases, we are at a tipping point on the forefront of agricultural development. Sustainable agroecological processes that will both feed the growing world 
population and create healthy ecosystems based on environmental stewardship are needed to reverse the negative environmental footprint of global agriculture.

Clearing land for agricultural activities and timber harvesting, including croplands, pastures, and rangelands, has resulted in approximately 7 to 11 million $\mathrm{km}^{2}$ of forest loss in the past 300 years (Foley et al. 2005). One reason for the alarming increase in tropical rainforest deforestation worldwide is the shift in the scale of farming practices (Rudel et al. 2009). Rainforest ecosystems have been transformed into large areas of agricultural lands through increased economic development, increased demand for agricultural exports on the international market, and governmental policies that have encouraged clearing the land for agricultural purposes. Tropical rainforests are being destroyed at alarming rates to create agricultural landscapes for the burgeoning global markets of beef, soybean, palm oils, and myriad other international crops (Barona et al. 2010). The authors also note one of the greatest drivers of land-use change and tropical deforestation throughout Latin America is agriculture.

A case study of West African rainforests conducted by Norris et al. (2010) has shown $80 \%$ of these rainforests have been transformed into patchworks of agricultural matrices, resulting in catastrophic losses of species diversity. According to Perfecto and Vandermeer (2008), if conservation efforts fail to implement sustainable agroecosystems in tropical forests, biodiversity protection in the tropics will be virtually impossible. However, as rainforest destruction continues to receive international media attention, we must be mindful that agricultural expansion and intensification occurs not only in the 
tropics but also worldwide and is an issue that must be addressed at local, regional, and global scales.

\section{Agriculture as a driver of global biodiversity loss}

Agricultural intensification has led to unprecedented losses of species worldwide. According to an article by Tscharntke et al. (2005), agricultural activities create fragmented landscapes, which cause small isolated patches of species to go extinct. Scientists do not know the number of species inhabiting our planet, nor do they know exactly how many species have been extirpated in past centuries. However, studies have shown approximately 150 species go extinct each day (Pimentel et al. 1992). Letourneau and Bothwell (2008) note biodiversity loss not only affects individual species but changes the complex structure and equilibrium environments need to maintain healthy ecosystems. These oversimplified environments lead to intensified pest outbreaks, as well as a reduction in critical components of an ecosystem, such as pollinators (Letourneau and Bothwell 2008). Monocultures, for example, have very low levels of diversity and consequently are subject to increased crop losses due to insect and pest outbreaks (Matson et al. 1997).

Disturbing of wildlife through agricultural activities has been linked to the transmission of infectious diseases in humans. For example, tropical deforestation, largely driven by agricultural activities, has been linked to the upsurge of malaria in Africa, Asia, and Latin America. Thus, habitat destruction and biodiversity loss is a paramount concern for human health, as approximately 75\% of human diseases can be

correlated to wild or domestic animals. A study by Tsegaye (1997) on the biodiversity of 
farms in Ethiopia documented that many farms are losing the genetic biodiversity of their plants. This was due to myriad factors, including severe droughts, deforestation, habitat destruction, and agricultural expansion and intensification. Tsegaye notes biodiversity is usually thought of in terms of flora and fauna; however, the term also encompasses plant genetic resources, the interaction of livestock in the environment, and the role soil microorganisms play in maintaining healthy and diverse ecosystems (Tsegaye 1997).

\section{Natural enemies in agricultural systems}

Natural enemies are vital components of agroecosystems and are consistently used as agents of biological control. Worldwide, nearly 2000 arthropod species, the majority of which are parasitoids, have been used as biological control agents (Letourneau et al. 2009). In United States agricultural lands alone, natural enemies and parasitoids provide approximately $\$ 4.5$ billion in pest control services (Al-Dobai et al. 2012). Species richness of predatory and carnivorous arthropods is also important in maintaining functional biodiversity in ecosystems and suppressing herbivorous arthropods. According to Letourneau et al. (2009), an increase in the species richness of natural enemies results in higher herbivore suppression. Natural enemy suppression of herbivores is a process encompassing at least $50 \%$ of all species on Earth. Worldwide, pest outbreaks and defoliation caused by herbivorous arthropods has caused immense amounts of damage both ecologically and economically, causing pest suppression to be a major concern of farmers (Letourneau et al. 2009).

Trophic-level interactions play a crucial role in maintaining the balance and central ecosystem functioning of agricultural systems. The community structure of 
agricultural systems is shaped by both "bottom-up" factors, such as the availability of resources, and "top-down” factors, including the presence of natural enemies. Interactions among trophic cascades are complex and controversial. Furthering our understanding of trophic-level interactions is essential to understanding the basic mechanisms of agroecosystems. For example, Dyre and Gentry (1999) have shown that parasitoids in agroecosystems were not effective at controlling generalist pests and were more successful at controlling specialists. They also found the same parasitoids were more effective at controlling aggregated pests, compared to sessile insects. Their study provides important insight into mechanisms of biological control, as it suggests using parasitoids against gregarious pests will yield greater success rates than using parasitoids on solitary larvae.

Component communities is the term ecologists use for the larger interconnected systems formed between arthropods and their surrounding plant vegetation. A study conducted by Root (1973) looked at the relationships between plants and arthropods in simple and diverse compound communities and provided the framework for a new paradigm on the associations between insects and habitat diversity. In this study, in which collard fauna were grown in both simple and diverse habitats, Root (1973) demonstrated the complexities between community composition and diversity of arthropods. In his results, Root found collards grown in more diverse habitats had lower biomass of herbivores than collards grown in simple habitats. His results, although pioneering for his time, now adhere to the widely accepted idea that pest severity is greater in simple environments. 
Root's (1973) results laid the foundation for the "Natural Enemies Hypothesis," stating predators and parasitoids are more effective in complex environments. However, Root goes on to note the underlying causes of this lower diversity in simple habitats are not straightforward. His results suggest although natural enemies do play a role in the difference in diversity between the two habitats, other factors are also at play, including what Root calls the "resource concentration hypothesis." Root notes many herbivorous predators find their host species concentrated in one area - one in which these species can meet all the necessities of their life cycle and thus remain and reproduce in that simple environment for long periods of time. However, more wide-ranging species will emigrate out of the area to find other food sources. The result is that simple environments will have greater densities of specialized herbivores, and the herbivore load becomes larger, although it will become unevenly distributed. In his experiment, Root (1973) illustrated how crops with simple to little surrounding plant diversity attract specialized herbivorous enemies who can meet and spend their entire life cycles in this simple environment, thus excessively increasing their numbers and the pest load of the community.

During the process of agricultural intensification, the diversity of compound communities that make up the ecosystem is greatly reduced and the landscape becomes a fragmented patchwork of interlaced crop-non-crop habitat types. An article by Letourneau et al. (2012) highlights the importance of heterogeneity in agricultural landscapes, noting the surrounding diversity of vegetation in agricultural matrices plays a crucial role in the long-term health of these fragile ecosystems. Fragmented 
agroecosystems are generally associated with low species richness and high rates of species extinction, which produce an area with low species diversity (Tscharntke et al. 2007). In a study on how natural enemy diversity is affected on the landscape scale, Tscharntke at al. (2007) note fragmented agricultural patchworks can be too small to support specific species and too far from diverse landscapes for organisms to emigrate to other communities. Tscharntke et al. go on to explain that although many of these communities may be large enough to support a particular species in the short term, they may not be able to ensure its survival on a long-term basis because the simplified landscape is isolated from more diverse landscapes. In the Midwest, one study found eliminating natural enemies from a soybean field could cause an increase in exotic aphid populations ten times that of their population with arthropod enemies present (Robertson and Swinton 2005).

Kruess and Tscharntke’s study (2000) supports the conclusion that habitat diversity plays a crucial role in species diversity. Peter Duelli et al. (1990) also note the survival of arthropods in agricultural landscapes is greatly determined by dispersal and the insect's ability to colonize. Agriculturally disturbed lands also diminish the resources available for natural enemies through habitat degradation and loss of food and shelter. Also, using natural enemies as a form of biological control in annual crops is especially challenging because the landscapes are more frequently disturbed due to short crop cycle rotations causing deleterious effects on the natural arthropod communities (Letourneau et al. 2012). 


\section{Plant diversity and pests}

The ecology of arthropods in response to vegetation diversity is an important principle to grasp in the field of agroecology. Root’s (1973) United Statesnatural enemies hypothesis states generalist predators and parasitoids should be more abundant in diverse agroecosystems than in simple ecosystems with less plant diversity. Supporting Root's enemies hypothesis, Andow (1991) showed herbivorous pests are less abundant on plants in complex environments. According to Andow, plants in complex environments have lower pest attacks because herbivores may have trouble locating them, leave more quickly, or have trouble finding them again after leaving. This study further stated agricultural lands with greater plant diversity have higher mortality rates from natural enemies than in simple agroecosystems. Letourneau et al. (2012) also found the mean abundance and richness of tachinids (parasitoid flies) increase in the surrounding landscapes of farms as semi-wild perennial plant vegetation increases. Multi-species agroecosystems also produce more stable crop production than simple agricultural landscapes (Altieri 2002). In an extensive review of the literature on plant diversity in agroecosystems, Letourneau et al. (2011) concluded more plant diversity in ecosystems results in greater herbivore pest suppression and reduction in crop damage.

\section{Importance of Diptera (flies) in agroecosystems}

Although some flies are considered pests, many Diptera taxa provide important ecosystem services such as pollination and biological control. For example, Syrphid and Tachinidae are two important parasitoids of herbivorous pests. The adults are pollinators, while their larvae are parasitoids and attack and regulate herbivorous arthropods (Tooker 
et al. 2006). The role of syrphid flies as natural enemies is predicated to be equal to that of voracious predators such as ladybirds and lacewings (Sajjad and Saeed 2010). Tachinid parasitoids are also important agents of biological control, regulating populations of pests such as Lepidoptera (moths) and Coleoptera (beetles). Tachinids are a very diverse and ubiquitous group of parasitoids; however, relative to their numbers ( 10,000 described species) and widespread range, little is known about their importance as parasitoids in agricultural lands and their importance as pollinators. In a study about how tachinids are affected by vegetation on surrounding landscapes of farms, Letourneau et al. (2012) found significant parasitism rates in the centers of crop fields, suggesting these flies are not only important natural enemies in unmanaged landscapes, but in managed agricultural landscapes as well.

\section{Multi-functional aspects of agricultural production}

Although the purpose of agriculture is to produce food, fiber, timber products, and other market goods and services, other multi-functional aspects of agroecosystems play important roles in the preservation of healthy ecosystems and contribute to the vitality of socio-economic markets (Boody et al. 2005). One important aspect of all agricultural endeavors is that it is a human enterprise fundamentally intertwined with and shaped by the complex inter-dynamic relationships driven by economic, political, and social forces. Thus, creating both economically and environmentally sustainable agricultural lands hinges on our ability to integrate and understand the interconnected social, ecological, and political factors involved (Robertson and Swinton 2005). Any market good, or other 
benefits humans obtain from agriculturally managed landscapes, can be referred to as an “ecosystem service” (Moonen and Bárberi 2008).

Agroecosystems are also important to preserve land, maintain landscape structure, sustainably manage natural resources, and conserve biodiversity (Boody et al. 2005). For example, responsibly-managed landscapes provide a clean water source, habitat for important animals such as pollinators, corridors and safe havens for wildlife, reduced risk of flooding and erosion, and myriad other benefits to the livelihoods of people across the planet (Robertson et al. 2004). One of the emerging facets of understanding modern agriculture is the new idea that properly managed agricultural landscapes can actually enhance biodiversity; thus, land use need not always equate to habitat and biodiversity loss. For example, studies in the tropics have shown shade-grown coffee supports a large richness of bird species, including endangered migratory birds, in higher densities in these agroecosystems than in virgin tropical rainforests (Tscharntke et al. 2005). Although more studies such as the previously mentioned are beginning to emerge in the scientific literature, we currently have an ambiguous understanding of the interconnections between biodiversity and agricultural landscapes and their subsequent ecosystem services. Our obscure understanding of this relationship points to the complexity of ecosystem functioning and will hopefully serve as a catalyst for future research to include a scientific framework integrating both biodiversity and ecosystem services into the discussion (Balvanera et al. 2001).

Agricultural landscapes can also act as buffer zones against insect-borne diseases and provide soil stabilization through plants. Managing the landscapes is important 
because many of these ecosystem services are irreplaceable or, if the technology exists to replace them, it is exorbitantly expensive (Palmer et al. 2004). Thinking of agricultural lands as multi-functional ecosystems has facilitated the rise of new facets of ecology. For example, the disciplines of agricultural ecology, landscape ecology, ecosystem management, and earth systems science are all newly developed and are innovative ways to look at agricultural landscapes (Robertson et al. 2004).

Other multifaceted aspects of agricultural lands include the interactions occurring between agroecosystems and the surrounding landscapes. Agroecosystems surrounded by a landscape with high biodiversity have been shown to reduce pest attacks. For example, studies have shown hedgerows and woodlots provide habitats for animals that prey on pests in neighboring agroecosystems (Matson et al. 1997). A renewed interest in intercropping, integrated pest management (IPM), and other aspects of ecologically designed systems shows national and international agricultural research is moving in the right direction. For example, ecological studies have shown that by using IPM techniques coupled with manipulating trophic levels, we can control pest populations and minimize crop damage without the damaging environmental effect of pesticides (Matson et al. 1997). Natural pest control in diverse landscapes is just one of the countless ways in which agriculture can provide environmental benefits to society. Agriculture has the possibility to go beyond its one-dimensional role of providing food and fiber to a role in which it can mitigate and become part of the solution to environmental problems, such as water shortages, biodiversity loss, and climate change (Robertson et al. 2004). 
The age of agricultural intensification has seen the advent of many technological innovations to facilitate the growth of the agro-business industry. However, this era of agricultural expansion has provided a weak framework for farmers who want to control insects and other pests through crop diversity and other alternative methods to pesticides. The common use of pesticides to kill insects on crops has created the universal problem of pesticide resistance, as well as myriad other deleterious environmental effects. Integrated pest management (IPM) uses natural plants, biological controls, and agrochemicals to kill pests. The use of IPM in agricultural sectors helps provide food and fiber necessary for people’s livelihoods while also preserving and promoting biologically diverse ecosystems. However, it has not been extensively implemented in the agricultural sector and continues to be practiced in only limited areas of agricultural lands production around the world.

Creating sustainable agriculture while providing for a hungry planet is no easy task. Global sustainable agriculture is a challenge requiring the merging of interdisciplinary sciences and cooperation on a manifold scale, often through long-term research projects. Tackling the issue of sustainable agroecosystems should follow the parameters of the colloquial saying, "think globally, act locally.” Agricultural intensification and expansion is a global issue that cannot be solved at the individualfarm level alone (Robertson et al. 2004). Ecologically sound science must be integrated with agricultural policies aiming to understand the interrelations between healthy ecosystems and human livelihoods (Palmer et al. 2004). A new era of agricultural research acknowledging vital ecosystem services, human involvement in agricultural 
landscapes, and innovative ecological strategies incorporating interdisciplinary work into agricultural policies are needed to achieve the goals of sustainable agriculture. The nature of our agricultural system is it is not sustainable. We cannot keep feeding a growing world population with agricultural practices that destroy the environment, thus undermining the whole process of agricultural production.

\section{Agriculture in the United States}

In the contiguous United States, approximately $50 \%$ of the land is devoted to agricultural practices (Robertson et al. 2004, Stuart 2009). According to an article by Ray et al. (2003), more than 2 billion acres of land in the United States is either agricultural or forest land. The remaining landscapes are made up of urban areas, parks, swamps, and desert-lands unusable for agricultural purposes. Through ingenuity of infrastructure and capital-intensive mega-projects, the United States has created a new transnational policy network of agricultural expansionism that has transformed landscapes throughout the world. United States agricultural policies are based upon internationalized imperialism. An article by Goldman (2007) articulates the United States' hegemonic control over the global agricultural sector exerted through refusal of the World Bank's and IMF's demands to give up their annum agricultural subsidies. However, as a precondition to debt restructuring and loans, southern African nations were required to eliminate their agricultural subsidies, while the United States, with much

greater monetary leverage and power, simply refused and continued to obtain annual agricultural subsidies of $\$ 300$ billion (Goldman 2007). 
The United States produces eight major crops - corn, wheat, soybeans, oats, barley, cotton, rice, and sorghum. These eight major crops make up 74\% of the total production of crops (Ray et al. 2003). The vast majority of these lands are privately owned, with 99\% of the nation's cropland and 61\% of rangeland in private hands (Stuart 2009). Because the US has such a large agricultural industry, the government subsidizes many agricultural commodities through agricultural practices. For example, between 1995 and 2002, corn, wheat, soybeans, cotton, and rice received 89\% of the $\$ 91.2$ billion in "commodity payments" to enhance the income of farmers. As a result of the large subsidies, myopic policies, and market infrastructure, the United States continues to produce agricultural surpluses, resulting in environmental destruction, fewer farmers, and a declining economic sector of rural areas (Boody et al. 2005). Furthermore, most United States policies regarding conservation of agricultural lands have been effected through land-retirement programs, rather than on working agricultural lands. According to Boody et al. (2005), United States policies should address the interrelated environmental, social, and economic facets of agriculture and the subsequent benefits that can be acquired from sound policies.

The vast majority of intensive agricultural lands in the United States are in a state of deterioration. For example, according to an article by Jackson (2002), approximately $90 \%$ of agricultural lands in the United States are losing soil 17 times faster than it can be replaced. If soil loss continues at this rate over the next 10 years, good crop yields from non-fertilized or irrigated lands are projected to drop by $20 \%$. The degradation of soils on agricultural lands, coupled with damages to infrastructure and both freshwater and 
aquatic ecosystems, is costing the United States government $\$ 44$ billion a year in damages (Jackson 2002). In his article, Jackson notes the relationship between soil erosion in the United States and our growing dependence on fossil fuels. In the age of fossil fuels, we are substituting efficient soil carbon for the extremely inefficient fossil fuel carbon. An example of the inefficiencies of conventional agriculture in the United States can be seen in the ratio between the numbers of fossil fuel calories required to produce food calories. To produce one food calorie, the United States agricultural sector uses 10 fossil fuel calories (Jackson 2002).

Another facet of the inadequate agricultural system in the United States is the dependence on synthetic agro-chemicals and fertilizers. Reliance on pesticides is apparent in all sectors of conventional agriculture. For example, herbicides--pesticides that kill weeds--are used by more than $90 \%$ of United States corn farmers. Atrazine, one of the most universally used herbicides sprayed on corn crops, is also one of the most common pesticides found in streams, rivers, and groundwater sources (Pimentel et al. 2005). The intensive use of pesticides is not only an environmental issue, but poses serious risks to human health and has economic consequences as well. For example, the United States pays about \$12 billion annually in environmental and healthcare damages from pesticide use (Pimentel et al. 2005).

Studies have shown $1 \%$ or less of agro-chemicals reach their intended pests; the other 99\% of applied pesticides wreak havoc on human health and the environment both on- and off-site (Jackson 2002). Despite such large inefficiencies, insecticide use in the United States has gone from 15 million pounds in 1950 to more than 125 million pounds 
today. During the same timeframe, the number of crops lost to pests went from $7 \%$ to 13\% (Jackson 2002). These problems are not confined within the borders of the United States. American farm policies influence and shape the global markets and set examples for many nations wishing to follow in the footsteps of the industrial agriculture giant (Ray et al. 2003). Thus, United States policymakers must remember agricultural policies implemented in the United States have consequences beyond our borders, and repercussions of our agricultural policies influence international communities. The most intensively tilled and pesticide-extensive agricultural lands in the United States are farms with annual vegetables. Consequently, using bio-control methods to reduce pesticide use and disturbance on annual vegetable crop farms would result in a significant reduction in pesticide use (Letourneau et al. 2012).

\section{California agriculture}

Despite containing less than $4 \%$ of the nation's farms and ranches, California is responsible for $11.2 \%$ of total United States production in agricultural goods (United States Department of Agriculture 2010). For example, an article by Brodt et al. (2006) noted farms in California's Central Valley account for half the nation's total supply of fruits and nuts. California's Mediterranean-like climate, coupled with widespread irrigation infrastructure, has created a reputation for producing some of the highest quality agricultural products in the world. California crops are considered of such superior quality that even the strictest of international buyers, such as Japan, purchase many products from California farms (Brodt et al. 2006). The Central Coast region of California, the area of research for this study, is one of the most productive and lucrative 
agricultural regions in the country. The Central Coast contains seven counties: Monterey, Santa Cruz, San Benito, Santa Clara, Santa Barbara, San Mateo, and San Luis Obispo. Central Coast farms produce more than 200 different types of crops and annually bring in up to $\$ 5$ billion. Monterey County encompasses the Salinas Valley, known as the "salad bowl of America," which generates up to 82,000 tons of lettuce every year (Stuart 2009, Stuart et al. 2006). California is considered a "biodiversity hotspot," and the different microclimates contribute to the wide diversity of species adding to the uniqueness of the wildlife in the state. California has more species than any other state in the nation and also contains the highest number of endemic species (Bunn et al. 2005). Thus, intensive agricultural practices in this region with such distinct but fragile communities of organisms can cause widespread damage to an environmentally unique sensitive area.

\section{California agriculture on the Central Coast}

The Central Coast is the epitome of the industrialization and specialization of agriculture and exemplifies the trend of agricultural intensification in the United States. Central Coast farmers use crop specialization, external outputs, and highly developed infrastructural and irrigational systems. This region, through its agriculture, is an important part of California's economy as the center for the exportation of many vegetables throughout the United States and worldwide. For example, Monterey County is the center for production of "leafy greens," including spinach, chard, kale, broccoli, and other vegetables. Agriculture brings in $\$ 2.2$ billion and accounts for roughly $40 \%$ of Monterey County's economy. Monterey County alone produces 10\% of the United States’ overall vegetable product (Letourneau et al. 2012). Farmers on the Central Coast 
are extremely competitive, selling to major companies such as Dole® and Fresh Express ${ }^{\circledR}$, which together control $70 \%$ of the leafy greens market in the United States (Stuart 2009). The diverse landscapes on California's Central Coast provide habitat for an assortment of native plants in the regions' heterogeneous ecosystems, including wetlands, chaparral, oak woodlands, and coastal terrace prairies (Letourneau et al. 2012). Intensive agricultural production on California's Central Coast has had devastating environmental impacts on the region’s natural resources. For example, Monterey County applies large amounts of pesticides to the intensively tilled monoculture farms making up the majority of crops in the region and is ranked fourth in the State of California for the total amount of pesticides applied (Bunn et al. 2005). Widespread monoculture production, coupled with intensive tillage and pesticide application, has caused extensive damage to the region's rivers, streams, lakes, and wetlands (Stuart et al. 2006). According to Stuart et al. (2006), intensive agricultural practices have caused ubiquitous water quality problems on the Central Coast. Agricultural irrigation accounts for a majority of the region's water consumption, comprising 70\% of the Central's Coast water usage (Bunn et al. 2005). The region houses important watersheds, including the federally protected Monterey Bay National Marine Sanctuary and Elkhorn Slough, one of the nation's last large remaining wetlands. Seventy-five percent of the landscapes surrounding these essential watersheds are under agricultural production. The water entering the National Marine Sanctuary has consistently failed to meet water quality standards due to high levels of nutrients, pesticides, and sediment (Stuart et al. 2006). California annually applies more than 100 
million pounds of pesticides to both agricultural and urban areas, with devastating impacts on birds, fish, mammals, and the terrestrial and aquatic habitats of these species (Kegley et al. 1999).

The principal agricultural crops produced on the Central Coast are strawberries and assorted vegetables, making the land extremely susceptible to nutrient runoff. Vegetable systems are prone to nutrient leaching because of the intensive tillage required and the low efficacy of nutrients. The resulting nutrient runoff from vegetable production causes eutrophication of aquatic environments and increased sediment levels in rivers, streams, and lakes, posing imminent threats for the endangered steelhead and Coho salmon, both extremely susceptible to even the smallest changes in sedimentation (Stuart et al. 2006). Pesticide runoff in the region contributes to a reduction in species diversity and causes the decline of animal and plant communities through habitat loss, diminished food supplies, and damaged reproductive organs (Kegley et al. 1999).

\section{California Central Coast ecosystems}

The heterogeneity of the region's landscape has created extraordinary levels of biodiversity. The Central Coast provides habitat for 482 vertebrate species: 283 birds, 87 mammals, 42 reptiles, 25 amphibians, and 45 fish. Thirteen of the vertebrate species are endemic to the Central Coast region and one is endemic to California. The endemic species of the Central Coast are the Santa Cruz long-toed salamander (Ambystoma macrodactylum croceum), black legless lizard (Aniella pulchra nigra), Moro Bay kangaroo rat (Dipodmys heermanni morroensis), Big-eared kangaroo rat (Dipodmys venustus elephantinus), Pajaro/Salinas hitch (Lavinia-exlicauda harengus), Monterey 
roach (Lavinia-symmetricus subditus), Monterey vole (Microtus-Californicushalophilus), San Francisco dusky-footed woodrat (Neotoma fuscipes annectens), Monterey dusky-footed woodrat (Neotoma macrotis-Luciana), Salinas pocket mouse (Perognathus inornatus psammophilos), Salinas harvest mouse (Reithrodontomys megalotis distichlis), Monterey shrew (sorex ornatus salarius), and the Monterey vagrant shrew (Sorex vagrans paludivagus) (Table 1). The number of arthropod species in the region is unknown; however, 60 invertebrate species of the Central Coast are registered on the Special Animal's List (Table 2). Thirty-two of the 60 arthropod species are endemic to the Central Coast, and another 25, while not endemic to this region, are endemic to California (Bunn et al. 2005).

Table 1: Endemic Species of the Central Coast

\begin{tabular}{|c|c|}
\hline Ambystoma macrodactylum croceum & Santa Cruz long-toed salamander \\
\hline Aniella pulchra nigra & Black legless lizard \\
\hline Dipodmys heermanni morroensis & Moro Bay kangaroo rat \\
\hline Dipodmys venustus elephantinus & Big-eared kangaroo rat \\
\hline Lavinia exilicauda harengus & Pajaro/Salinas hitch \\
\hline Lavinia symmetricus subditus & Monterey roach \\
\hline Microtus californicus halophilus & Monterey vole \\
\hline Neotoma fuscipes annectens & San Francisco dusky-footed woodrat \\
\hline Neotoma macrotis Luciana & Monterey dusky-footed woodrat \\
\hline Perognathus inornatus psammophilus & Salinas pocket mouse \\
\hline Reithrodontomys megalotis distichlis & Salinas harvest mouse \\
\hline Sorex ornatus salarius & Monterey shrew \\
\hline Sorex vagrans paludivagus & Monterey vagrant shrew \\
\hline
\end{tabular}


Table 2: Special Status Invertebrates of the Central Coast

\begin{tabular}{|c|c|}
\hline Ablautus schlingeri & Oso Flaco robber fly \\
\hline Adela oplerella & longhorn moth \\
\hline Aegialia concinna Ciervo aegilian & scarab beetle \\
\hline *Ammopelmatus muwu & Point Conception Jerusalem cricket \\
\hline *Areniscythris brachypteris & Oso Flaco flightless moth \\
\hline Branchinecta longiantenna & Longhorn fairy shrimp \\
\hline Caecidotea tomalensis & Tomales isopod \\
\hline *Calicina minor & Edgewood blind harvestman \\
\hline *Calicina arida & A harvestman; no common name \\
\hline *Calileptoneta ubicki & Ubick’s calileptoneta spider \\
\hline Ceratochrysis longimala & A chrysidid wasp; no common name \\
\hline Certaochrysis menkei & Menke’s chrysidid wasp \\
\hline Chrysis tularensis & Tulare chrysidid wasp \\
\hline Cicindela hirticollis gravida & Sandy beach tiger beetle \\
\hline *Cicindela ohlone & Ohlone tiger beetle \\
\hline Coelus globosus & Globose dune beetle \\
\hline Coelus gracilis & San Joaquin dune beetle \\
\hline Desmocerus californicus dimorphus & Valley elderberry longhorn beetle \\
\hline *Euphilotes enoptes smithi & Smith's blue butterfly \\
\hline Euphydryas editha bayensis & Bay checkerspot butterfly \\
\hline *Fissilicreagris imperialis & Empire Cave pseudoscorpion \\
\hline *Helminthoglypta sequoicola consors & Redwood shoulderband (snail) \\
\hline *Helminthoglypta walkeriana & $\begin{array}{l}\text { Morro shoulderband (=banded dune) } \\
\text { snail }\end{array}$ \\
\hline *Hubbardia secoensis & A schizomid arachnid; no common name \\
\hline Hydrochara rickseckeri & Ricksecker's water scavenger beetle \\
\hline Hydroporus leechi & Leech's skyline diving beetle \\
\hline Icaricia icarioides missionensis & Mission blue butterfly \\
\hline *Icaricia icarioides moroensis & Morro Bay blue butterfly \\
\hline *Idiostatus kathleenae & Pinnacles shieldback katydid \\
\hline Incisalia mossii bayensis & San Bruno elfin butterfly \\
\hline *Lichnanthe albipilosa & White sand bear scarab beetle \\
\hline Lichnanthe ursina & Bumblebee scarab beetle \\
\hline Linderiella occidentalis & California linderiella \\
\hline Lytta hoppingi & Hopping’s blister beetle \\
\hline Lytta morrisoni & Morrison’s blister beetle \\
\hline *Meta dolloff & Dolloff Cave spider \\
\hline *Microcina edgewoodensis & Edgewood Park micro-blind harvestman \\
\hline Microcina homi & Hom’s micro-blind harvestman \\
\hline
\end{tabular}


Table 2 (continued)

\begin{tabular}{|c|c|}
\hline *Minymischa ventura & Ventura chrysidid wasp \\
\hline *Necydalis rudei & Rude’s longhorn beetle \\
\hline *Neochthonius imperialis & Empire Cave pseudoscorpion \\
\hline Nothochrysa californica & San Francisco lacewing \\
\hline *Optioservus canus & Pinnacles optioservus riffle beetle \\
\hline *Philanthus nasalis & Antioch sphecid wasp \\
\hline *Polyphylla barbata & Mount Hermon (=barbate) june beetle \\
\hline *Polyphylla nubila & Atascadero june beetle \\
\hline *Protodufourea wasbaueri & Wasbauer's protodufourea bee \\
\hline *Protodufourea zavortinki & Zavortink's protodufourea bee \\
\hline *Socalchemmis monterey & Monterey socalchemmis spider \\
\hline *Speyeria adiaste adiaste & Unsilvered fritillary \\
\hline Speyeria zerene myrtleae & Myrtle's silverspot \\
\hline *Stygobromus mackenziei & Mackenzie's cave amphipod \\
\hline *Thessalia leanira elegans & Oso Flaco patch butterfly \\
\hline Trachusa gummifera & A megachilid bee; no common name \\
\hline *Trimerotropis infantilis & Zayante band-winged grasshopper \\
\hline *Trimerotropis occulens & Lompoc grasshopper \\
\hline Tryonia imitator & Mimic tryonia (=California \\
& brackishwater snail) \\
\hline
\end{tabular}

*denotes endemic taxa of Central Coast

Coastal ecosystems provide habitats for various shorebirds including the Western snowy plover (Charadrius alexandrinus), California Clapper Rail (Rallus longirostris obsoletus), willet (Tringa semipalmata), whimbrel (Numenius phaeopus), long-billed curlew (Numenius americanus), and marbled godwit (Limosa fedoa). Coastal estuaries support critical habitats for anadromous and marine fish, including Coho Salmon (Oncorhynchus kisutch) and Steelhead (Oncorhynchus mykiss). The largest estuaries in the region include Elkhorn Slough and Morro Bay. Other important wetlands include the Pajaro, Salinas, and Santa Maria watersheds. Chaparral ecosystems provide critical habitat for the Santa Cruz and Pacific kangaroo rat species as well as various bird species, 
including California quail (Callipepla californica), sage sparrow (Amphispiza belli), and the California thrasher (Toxostoma redivivum) and Costa's hummingbird (Calypte costae), both declining species. The wide-ranging wildlife that roam in the Coastal mountain ecosystems includes mountain lions (Puma concolor), bobcats (Lynx rufus), coyotes (Canis latrans), and rare species including the California spotted owl (Strix occidentalis), American badger (Taxidea taxus), peregrine falcon (Falco peregrinus), and golden eagle (Aquila chrysaetos). Oak woodland ecosystems support a diversity of species, including 200 plants species, 300 vertebrates, and 5,000 invertebrates (Bunn et al. 2005).

Reflecting the explosive growth and development throughout California, the Central Coast Region saw a population increase of 10\% between 2000 and 2010 (United States Census Bureau 2011). The amount of land devoted to urban development increased by 54\% between 1980 and 2002. The greatest amount of population growth has occurred along the coast, with inland areas devoted to large ranches and agricultural farms. Coastal cities with the largest populations include Santa Cruz, Santa Barbara, Monterey, Seaside, and Marina. The growing population pressures have pushed growth and development from urban areas to surrounding farmland and rural parts of the region. The expansion into rural areas coupled with intensification of agriculture is putting great stress on the region's wildlife. Biodiversity is suffering due to increased runoff of agrochemicals, increased sedimentation in streams and lakes, diversion and over-use of water resources, and habitat loss and fragmentation (Bunn et al. 2005). 


\section{The agricultural crisis: The need for an interdisciplinary approach}

Industrial agricultural intensification is a serious global environmental issue that merits worldwide attention, similar to that of other global environmental problems including tropical rainforest destruction and climate change. Sustainable agroecological measures must be implemented through practical solutions addressing the complex and interconnected biological and social aspects of agricultural systems. To combat the problem of industrial agricultural intensification, it is important to understand the myriad complexities involved, and then begin an analysis of how to implement sustainable agricultural practices.

Understanding the complex interconnected factors playing a role in global agricultural intensification and the ensuing environmental destruction is critical to developing a strategic and analytic project that focuses on one piece of the overall picture. Philip Fearnside (2008) notes the importance of understanding the underlying social, cultural, and political aspects of tropical rainforest deforestation, a concept that must also be applied to the agricultural sector. Applying Fearnside’s analysis to the agricultural sector, conservation policies that do not take into account the multifaceted political and economic drivers of agricultural intensification will fail. Finding local solutions to a global agricultural crisis will require a better understanding of the continuum of social processes at play. The complex inter-dynamic relationships between the economic, political, and social forces driving agricultural intensification must be addressed to preserve and protect the biodiversity and food security of our world's most endangered and fragmented ecosystems. 


\section{Problem Statement}

Modern intensification of industrial agriculture has significantly modified California’s terrestrial landscapes and is one of the biggest drivers of biodiversity loss, habitat fragmentation, and pollution. Understanding the relationship between insect biodiversity and ecosystem functioning on farm landscapes is an important step in devising strategies to preserve diverse landscapes and biological communities throughout California’s farmlands. Biodiversity of insects, specifically parasitoids, is an important part of the functionality of these ecosystems.

\section{Framework of study}

This paper incorporated data from a study by Letourneau et al. (2012) on how vegetation affects tachinid fly abundance and diversity on 35 organic vegetable farms on the Central Coast. The study was conducted over 2 years (2005-2006) and 3 seasons: spring, summer, and fall. Their study analyzed only tachinid flies, although they collected Hymenopteran parasitoids as well. My study used part of the data from Letourneau et al. (2012) and measured how vegetation affects insects on two spatial scales, the large scale of 35 farms and a smaller scale within one farm.

\section{Objectives}

This study aimed to measure the relationship between insects and vegetation on two scales: the landscape-scale and the single-farm scale. The landscape-scale consisted of looking at the associations between parasitoid biodiversity and diversity of the adjacent landscapes at 35 organic vegetable farms on the Central Coast of California. This research evaluated how important these fragmented agroecosystems are and whether 
enhancing and protecting plant diversity on farms and their surrounding landscapes has measurable effects on beneficial insects, such as parasitoids. This study further addressed a poorly researched question, specifically, whether the diversity of on-farm vegetation increases the diversity of insects in the field. This portion of the study was conducted on a micro-scale - in one field at Live Earth Farm, an organic farm located in Watsonville, California.

\section{Hypotheses}

\section{Landscape-scale biodiversity.}

$\mathbf{H}_{1 \mathbf{a}}$ : Farms with greater levels of vegetation in the surrounding landscapes will harbor greater levels of parasitoid wasp biodiversity.

$\mathbf{H}_{\mathbf{1 b}}$ : Farms with greater levels of wild annual vegetation in the surrounding landscape will harbor greater levels of parasitoid wasp abundance.

\section{Farm-scale biodiversity.}

$\mathbf{H}_{2 \mathbf{a}}$ : Within a smaller area, biodiversity of insects will be greater in areas of greater on-farm biodiversity.

$\mathbf{H}_{2 b}$ : Within a smaller area, insect abundance will be greater in areas with a greater percentage of plant cover. 


\section{Methods}

\section{Study system}

Large-scale study. The large-scale part of this study took place on the Central Coast of California, situated along the Pacific Ocean stretching south of San Francisco to Santa Barbara, including Santa Cruz, Monterey, and San Benito counties. Santa Cruz and Monterey Counties are located along the Pacific Coast, whereas San Benito County is $46 \mathrm{~km}$ inland and does not have coastal access (Figure 1). This study involved 35 organic farms situated throughout the previously mentioned three counties (Figure 1). 

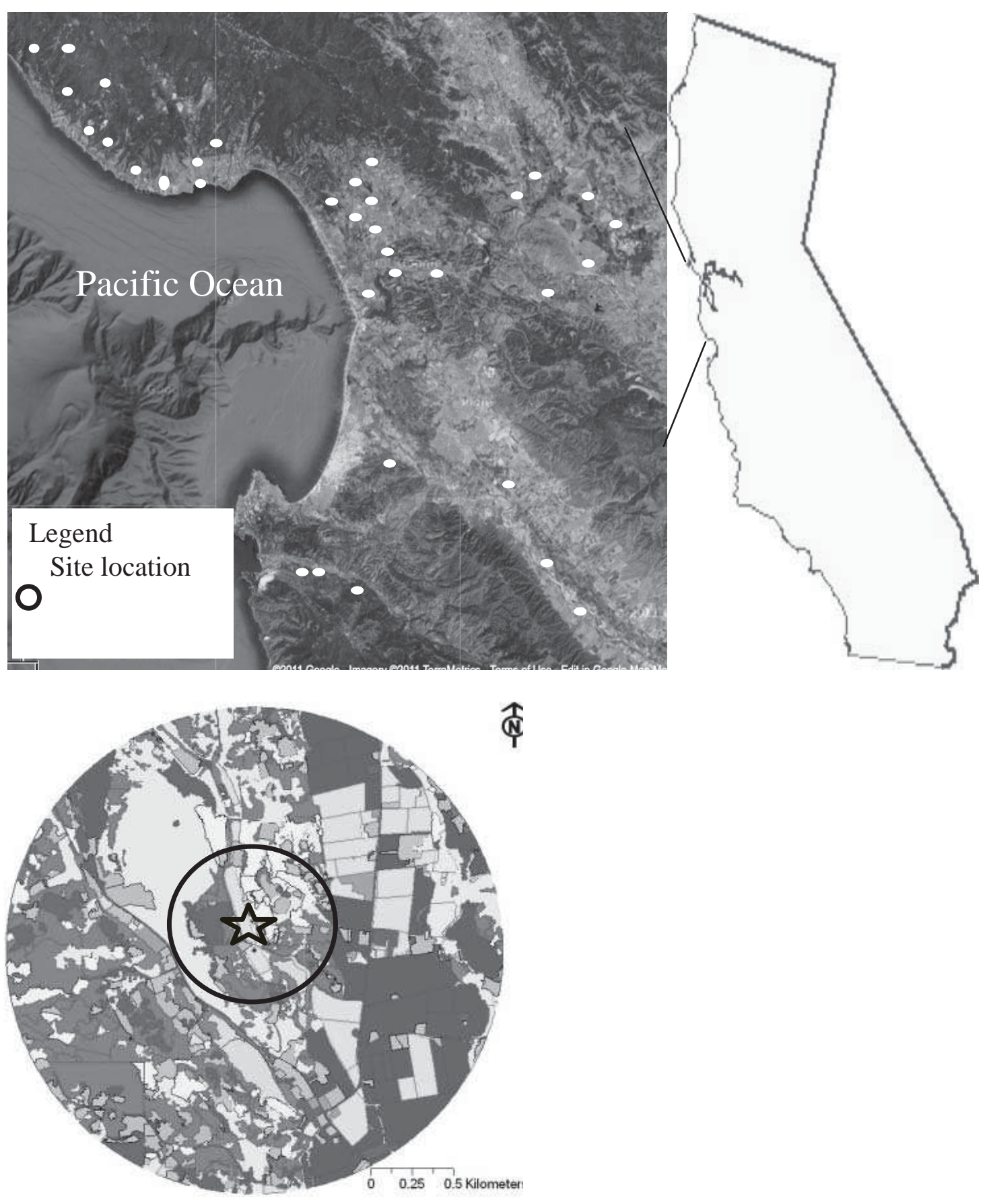

Figure 1. Map of Study Locations-Created by Sara Bothwell Allen 
The three counties have heterogeneous landscapes and contain differences in climate as well as geography and soils, which have created assorted ecological conditions supporting a wide range of species diversity. The geographic diversity of the region has created coastal, mountain, and desert-like ecosystems. Monterey and Santa Cruz counties comprise a rocky coastline, small mountain ranges, rivers, and valleys with rich alluvial soils, and xeric conditions in inland valleys and hills. The climate of San Benito County is much drier, and the vegetation shifts from maritime coastal scrub and chaparral to interior chaparral, grasslands, oak woodlands, and interior scrub. Due to the heterogeneity of the landscapes, these three counties contain numerous native plant species and a wide range of vegetation communities including coastal terrace prairies, oak woodlands, coastal scrub, chaparral, and wetlands. Endemic tree species include the Monterey Pine (Pinus radiata) and Santa Lucia Fir (Abies bracteata). The dominant species of the oak woodlands include coast live oak (Quercus agrifolia), valley oak (Quercus lobata), and blue oak (Quercus douglasii). The coastal wetland communities are made up of estuaries, lagoons, sloughs, tidal mudflats, and marshes (Bunn et al. 2005).

The climate of the counties ranges from moist marine layers with foggy patches along the coast in Monterey and Santa Cruz Counties, to the drier inland areas of San Benito County. Inland areas with chaparral and grassland ecosystems contain the lowest points of elevation among these Central Coast Counties. Riparian ecosystems in the inland valleys contain mainly sycamore, willow, alder, and cottonwood trees. 
The majority of the region's agriculture occurs in fertile river valleys and coastal terrace lands in the northern and southern regions of the counties. The region's rivers, valleys, and seasonally moist climate provide fertile alluvial soils that produce some of the nation's best farmland (Bunn et al. 2005). Two important agricultural sites for this study, the lower Salinas Valley, and the Pajaro Valley, are located within Santa Cruz, San Benito, and Monterey Counties. The Pajaro Valley spans all three counties, while the Salinas Valley is located in Monterey and San Benito Counties. The Salinas Valley is one of the most productive agricultural regions in California and produces such large amounts of lettuce and broccoli and other cole crops that it is often referred to as the "Salad Bowl of America” (Stuart 2009, Stuart et al. 2006). The principal crops grown within the Salinas Valley include lettuce, tomatoes, strawberries, and spinach.

The Pajaro Valley spans all three counties, but the center of agriculture in the valley is located near the city of Watsonville, a small farming community located south of Santa Cruz along Highway 1. Due to good soil conditions, a mild climate, access to water, and a skilled set of farm laborers, the Pajaro Valley is an extremely important agricultural region at both the state and national levels. Agricultural production accounts for approximately $30 \%$ of the land use in the Pajaro Valley (Stuart et al. 2006). The local economy is centered around the agricultural industry. This multi-million dollar industry employs thousands of workers located throughout the Pajaro Valley region. This valley produces a great number and variety of crops, both vegetables and fruits, but it is most famous for its berries, including strawberries, caneberries, and blueberries. California continues to lead the nation in strawberry and raspberry production. In 2009 alone, 89\% 
of the strawberries and raspberries produced in the United States were grown in California. Two of the top counties producing these berries in California are Santa Cruz and Monterey Counties, both within the Pajaro Valley region (Stuart et al. 2006).

Farm-scale study. A focused study was conducted at Live Earth Farm, a 32hectare organic farm in Santa Cruz County. Live Earth Farm is located in Watsonville, California, south of Santa Cruz, at the base of the foothills of the Santa Cruz Mountains, overlooking the Pajaro Valley (Figure 1).

Produce grown at Live Earth Farm includes organic vegetable crops and fruit orchards. The vegetables grown in September, the time period this study took place, included arugula, basil, bok choi, carrots, chards, collards, kale, mustard, cucumbers, garlic, green beans, chives, cilantro, parsley, lettuces, peppers (many kinds), potatoes, radishes, spinach, summer squash (different kinds), eggplant, tomatoes, turnips, and kohlrabi (stout version of cabbage). The fruits harvested in September were apples, concord grapes, pears, strawberries, raspberries, and blackberries. The farm soil is rich in nutrients, as it has been maintained over the years through the building up of organic matter by growing cover crops, rotating crops, composting, mulching, and low tillage practices. Cover crops help to reduce soil erosion, and certain ones grown on the farm, such as Sudan Grass, are known to have allelopathic properties that can reduce soil-borne diseases. Rotating in various cover crops every 2 years allows the land to recover and keeps the soil from becoming depleted.

The mission of the farm has been to produce healthy fruits and vegetables while mimicking nature to the highest possible degree and enhancing the biodiversity and 
native habitat of this agroecosystem. The growers have tried to prevent and control pest outbreaks by creating beneficial insect habitats, using barriers such as hedgerows, and releasing beneficial insects into the fields. The growers have also created natural habitats

around the fields, such as rows of sunflowers, to sustain beneficial insect populations, and planted a large diversity of crops to prevent pest outbreaks.

\section{Research design}

Landscape-scale biodiversity $\left(\mathbf{H}_{\mathbf{1 a}}, \mathbf{b}\right)$. To assess whether farms with higher levels of vegetation in the surrounding landscape harbored greater levels of parasitoid wasp biodiversity, I analyzed the relationship between parasitoids on-farm and on vegetation in adjacent landscapes near annual vegetable fields at 35 different farms. Data were collected in May, July, and September 2005 and 2006 by (Letourneau et al. 2012).

Farm-scale biodiversity $\left(\mathbf{H}_{2 \mathbf{a}, \mathbf{b}}\right)$. I tested whether the biodiversity of insects was greater in areas of greater on-farm biodiversity by measuring plant and insect diversity on Live Earth Farm. Both plant and insect diversity was measured in one heterogeneous field on the farm. The insects were collected on September 25, 2012. 


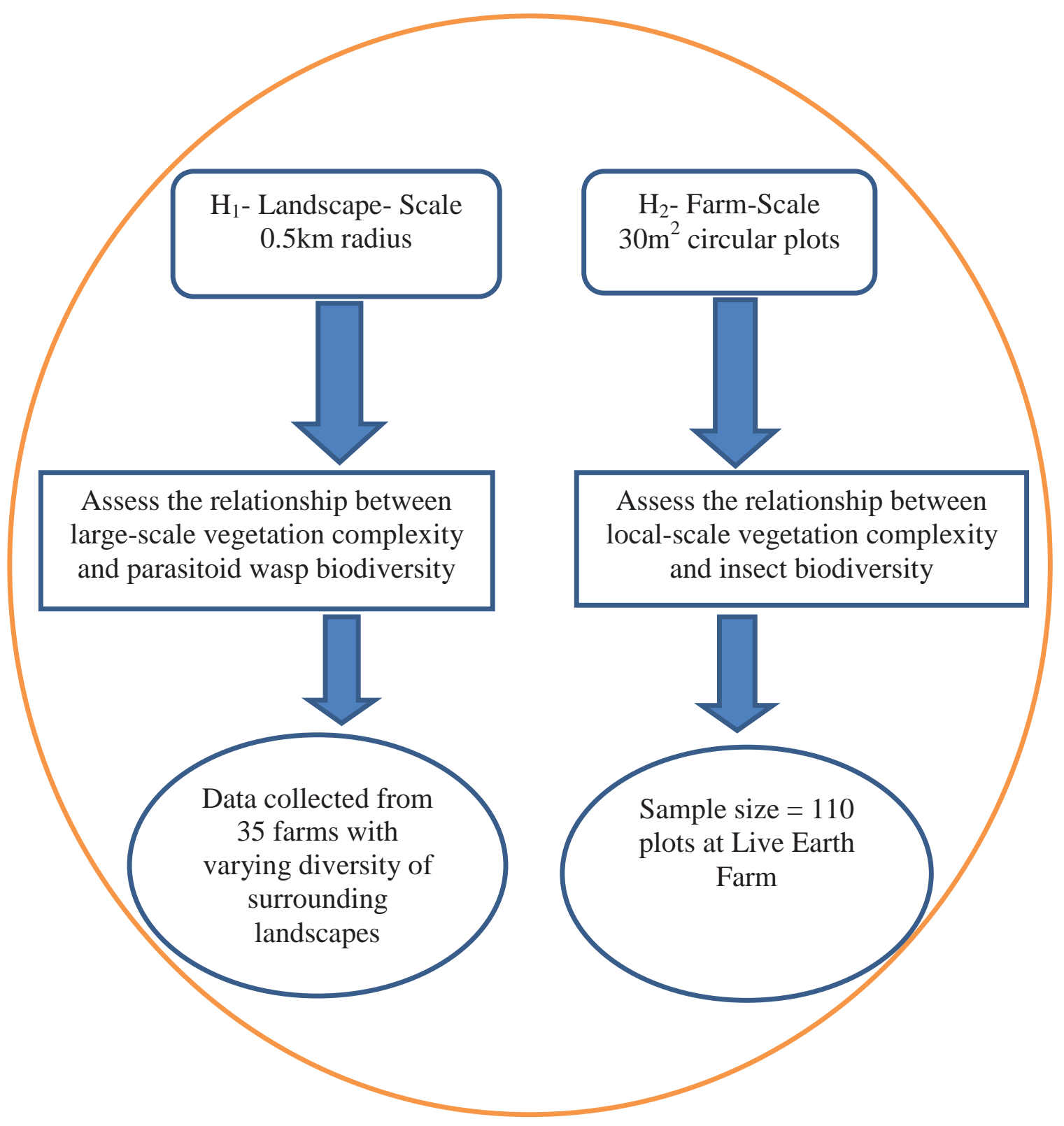

Figure 2. General Study Design 


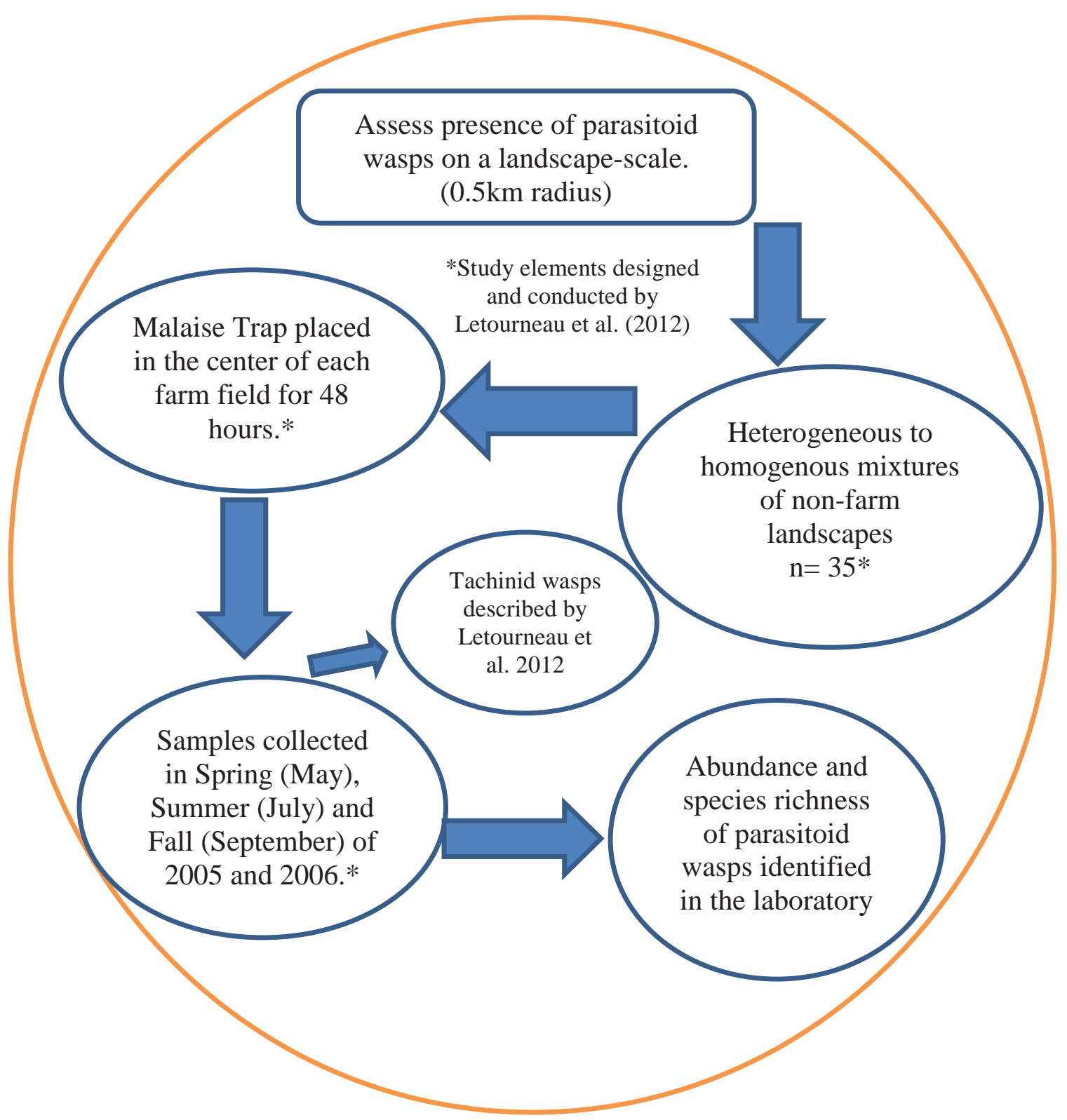

Figure 3. Study Design $\mathrm{H}_{1 \mathrm{a}}$ 


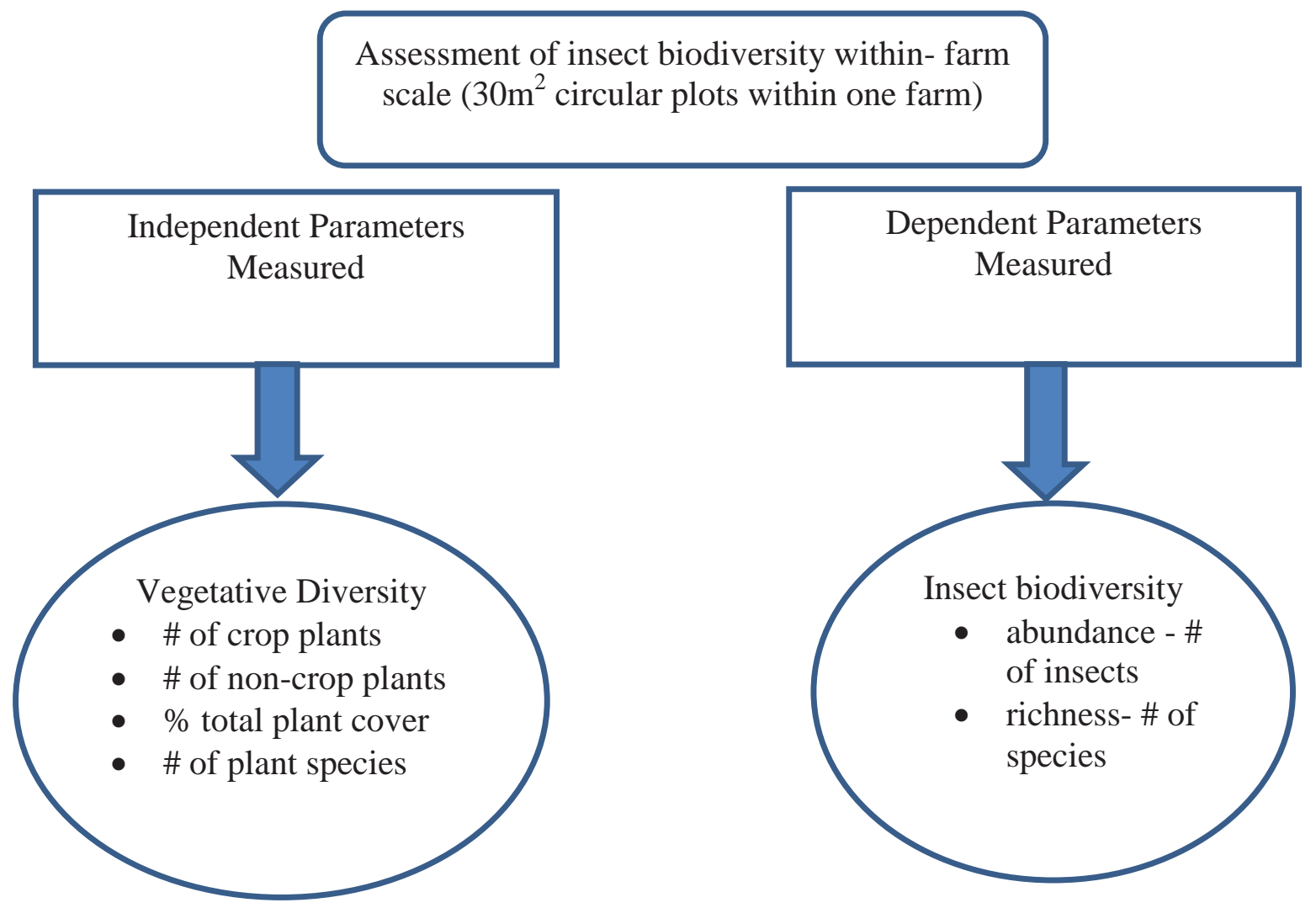

Figure 4. Study Design $\mathrm{H}_{2 \mathrm{a}, \mathrm{b}}$ 


\section{Results}

\section{H1a,b landscape-scale biodiversity}

Data collection. The data were collected by Deborah Letourneau, Sara Bothwell, and John Stireman III in May, July, and September of 2005 and 2006, and only Hymenoptera were sorted and analyzed for the study.

Sampling process. Malaise traps were placed for 48 hours in the centers of fields of 35 organic farms sampled. All tachinid flies, Ichneumonid parasitoids, and some Brachonid parasitoids were excluded from the data, as these insects were used in the study by Letourneau et al. (2012). The specimens were sorted, common insects were identified to morphospecies, and abundance and richness of all parasitoid wasps were counted. The farms were located within a $50 \mathrm{~km}$ north to south area by a 30-km inland area comprising the majority of the Central Coast farming region (Figure 1). The farms were chosen based upon the following conditions: the growers' willingness to partake in the experiment, the presence of green vegetables in the field, and a distance of at least 1 km separating the farms. The following vegetables were included in the crop rotations: cole crops comprising broccoli, cabbages, kale, lettuces, and a mix of squash, carrots, cucumber, and tomatoes and occasionally strawberries. The surrounding vegetation on the farms was measured using GIS, and the scales were within $1.5 \mathrm{~km}$ radius and $0.5 \mathrm{~km}$ radius of the farm. For the analysis of this study, the smaller scale of $0.5 \mathrm{~km}$ radius was used. The vegetation measured included semi-wild annual and perennial vegetation, woody vegetation, chaparral, annual forbs and grasses, and the percent of crop and noncrop cover. Crop diversity within each field was calculated using a categorical index of 
1-4. The surrounding vegetation on the farms was measured using GIS, and the scales were within $1.5 \mathrm{~km}$ radius and $0.5 \mathrm{~km}$ radius of the farm. For the analysis of this study, the smaller scale of $0.5 \mathrm{~km}$ radius was used. For more information, reference the published paper cited here (Letourneau et al. 2012).

Data analysis. The Hymenoptera specimens collected from the traps were examined using a dissection field AMScope microscope. The specimens from each subsample, Hymenoptera collected from one malaise trap, were counted and for every vial the abundance and richness was recorded. Hymenoptera abundance was obtained from counting all the specimens within each vial. Hymenoptera richness was identified by comparing key characteristics of each specimen and then categorizing them into morphospecies based on distinctive physiological features. Pictures of each taxonomic group were taken using a Leica DFC450 microscope camera with an optical lens model number Leica ZP6 APO. An AMScope microscope eyepiece camera MU500 was also used to take pictures of the specimens. The richness of the most common taxonomic groups from each vial was identified to family. After the total abundance and richness was counted for every subsample, Microsoft Excel@ 2007 was used to obtain the total abundance by summing the total abundance and richness within every vial.

To interpret the results of this research, the following analytic methods were used. Before running the analysis, basic statistics were conducted in SAS@ 9.2 and SYSTATC13 to determine the appropriate statistical tests to perform. A Principal Components Analysis (PCA) was conducted using the software program SAS@ 9.2, and Pearson's product moment correlation was performed before running the PCA to 
determine if any variables were highly correlated. PCA, a multi-variate statistical tool, allowed me to determine how vegetation in the surrounding landscape was affecting Hymenoptera. There were 57 independent variables included in the PCA, all of which were vegetation data collected from the surrounding landscapes of the farms. The independent variables that proved to be most important in the analysis were non-crop vegetation richness, wild annual vegetation, wild perennial vegetation, and landscape complexity. The dependent variables measured were Hymenoptera diversity, common numbers of Hymenoptera species, and the overall mean of Hymenoptera abundance and diversity. A linear regression was conducted in SYSTAT®13 to extrapolate the correlations and predictions between vegetation diversity in the surrounding landscape and Hymenoptera abundance and richness. The independent variables used in the regression analysis included vegetation richness, non-crop vegetation, perennial crops, wild annual vegetation, and landscape complexity. Letourneau et al. (2012) calculated The Landscape Complexity Index.

Outcomes. A total of 3,779 specimens were collected with 29 common morphospecies identified to either family or super-family. All specimens analyzed were in the order Hymenoptera and excluded tachinid flies, Ichneumonids, and some Brachonids, as sorted by Letourneau et al. (2012). Twenty-five percent of the 29 morphospecies were members of the superfamily Chalcidoidea. Braconidea made up the next-largest family, accounting for $16 \%$ of the morphospecies, while Cynopoidea made up $11 \%$ of the common morphospecies. The remaining $48 \%$ of morphospecies was made up of other families of parasitoid wasps important for biological control in the order 
Hymenoptera (Table 3). The greatest numbers of Hymenoptera abundances were caught in summer (July) of 2005 and 2006, with summer 2006 having the highest overall abundances of Hymenoptera. Spring 2006 had the lowest overall Hymenoptera abundances, while fall of both years sampled also had relatively low abundances. Species richness followed a similar pattern with summer of both sampling periods producing the highest mean richness. Spring 2006 again had the lowest mean richness, and fall again showed low richness for both years (Table 4).

Table 3: Common Insect Morphospecies at the Landscape-scale

\begin{tabular}{|c|c|c|c|c|}
\hline $\begin{array}{c}\text { Morphospecies } \\
\text { ID }\end{array}$ & Superfamily & Family & $\begin{array}{c}\text { \# of } \\
\text { individuals }\end{array}$ & Function \\
\hline A & Apoidea & Unknown 1 & 8 & Pollinator \\
\hline B & Apoidea & Unknown 2 & 14 & Pollinator \\
\hline C & Apoidea & Unknown 3 & 8 & Pollinator \\
\hline D & Chalcidoidea & Eluophidea & 16 & Parasitoid \\
\hline E & Chalcidoidea & Eucharitidae & 5 & Parasitoid \\
\hline F & Chalcidoidea & Pteromalidae 1 & 140 & Parasitoid \\
\hline G & Chalcidoidea & Pteromalidae 2 & 190 & Parasitoid \\
\hline H & Chalcidoidea & Pteromalidae 3 & 117 & Parasitoid \\
\hline I & Chalcidoidea & Pteromalidae 4 & 86 & Parasitoid \\
\hline J & Chalcidoidea & Pteromalidae 5 & 4 & Parasitoid \\
\hline K & Chalcidoidea & Pteromalidae 6 & 18 & Parasitoid \\
\hline L & Chalcidoidea & Unknown 1 & 17 & Parasitoid \\
\hline M & Chalcidoidea & Unknown 2 & 148 & Parasitoid \\
\hline N & Chalcidoidea & Unknown 3 & 8 & Parasitoid \\
\hline O & Chalcidoidea & Unknown 4 & 157 & Parasitoid \\
\hline P & Chalcidoidea & Unknown 5 & 11 & Parasitoid \\
\hline Q & Chalcidoidea & Unknown 6 & 5 & Parasitoid \\
\hline R & Chrysidoidea & Bethylidea 1 & 54 & Parasitoid \\
\hline S & Chrysidoidea & Bethylidea 2 & 1 & Parasitoid \\
\hline & & & & \\
\hline
\end{tabular}


Table 3 (continued)

\begin{tabular}{|c|c|c|c|c|}
\hline $\begin{array}{c}\text { Morphospecies } \\
\text { ID }\end{array}$ & Superfamily & Family & $\begin{array}{c}\text { \# of } \\
\text { individuals }\end{array}$ & Function \\
\hline T & Chrysidoidea & Dryinidae & 35 & Parasitoid \\
\hline U & Cynipoidea & Figitidae 1 & 121 & Parasitoid \\
\hline V & Cynipoidea & Figitidae 1 & 303 & Parasitoid \\
\hline W & $\underline{\text { Ichneumonoidea }}$ & Braconidea 1 & 329 & Parasitoid \\
\hline X & $\underline{\text { Ichneumonoidea }}$ & Braconidea 2 & 71 & Parasitoid \\
\hline Y & $\underline{\text { Ichneumonoidea }}$ & Braconidea 3 & 170 & Parasitoid \\
\hline Z & $\underline{\text { Ichneumonoidea }}$ & Braconidea 4 & 24 & Parasitoid \\
\hline AA & $\underline{\text { Ichneumonoidea }}$ & Braconidea 5 & 7 & Parasitoid \\
\hline AB & Proctotrupoidea & Diapriidae & 59 & Parasitoid \\
\hline AC & Vespoidea & Formicidea & 17 & Scavenger \\
\hline
\end{tabular}

Table 4: Overview of Landscape-scale Results

\begin{tabular}{|c|c|c|c|c|c|c|c|c|c|c|c|}
\hline & & \multicolumn{7}{|c|}{ parasitoid wasps } & \multirow{2}{*}{\multicolumn{3}{|c|}{$\begin{array}{c}\begin{array}{c}\text { tachinid flies } \\
\text { (Letourneau et al.) }\end{array} \\
\text { mean 2005-2006 }\end{array}$}} \\
\hline & & \multicolumn{3}{|c|}{2005} & \multicolumn{3}{|c|}{2006} & \multirow{2}{*}{ 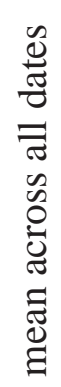 } & & & \\
\hline & & . & 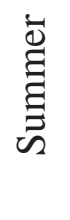 & $\underset{\text { 厌 }}{=}$ & 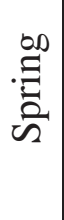 & 㐫 & $\underset{\widetilde{\widetilde{J}}}{\bar{\nabla}}$ & & 囟 & 它 & $\underset{[\widetilde{J}}{\bar{\nabla}}$ \\
\hline \multirow{2}{*}{$\begin{array}{c}\text { PC1 } \\
\text { (Complex } \\
\text { Landscape) }\end{array}$} & abundance & - & + & $\varnothing$ & $\varnothing$ & $\varnothing$ & $\varnothing$ & $\varnothing$ & + & + & + \\
\hline & richness & - & + & - & $\varnothing$ & $\varnothing$ & $\varnothing$ & $\varnothing$ & + & + & + \\
\hline \multirow{2}{*}{$\begin{array}{l}\text { Non-crop } \\
\text { Richness }\end{array}$} & abundance & - & - & - & - & $\varnothing$ & - & $\varnothing$ & & & \\
\hline & richness & $\varnothing$ & $\varnothing$ & $\varnothing$ & - & $\varnothing$ & $\varnothing$ & $\varnothing$ & & & \\
\hline \multirow{2}{*}{$\begin{array}{c}\text { PC3 } \\
\text { (Orchards, no } \\
\text { grasslands) }\end{array}$} & abundance & + & + & + & + & + & + & + & & & \\
\hline & richness & + & + & + & + & + & + & + & & & \\
\hline
\end{tabular}


Principle components. Principle component 1 was landscape complexity and Principle Component 3 was orchards with crops intermixed, but without grasslands.

Principle component 1. Principle component 1 (complex landscape) had various associations with mean Hymenoptera abundances for all sample dates of 2005. However, the only positive correlation was in summer, while both spring and fall produced negative correlations (Figure 5). Interestingly, there were no significant associations with principle component 1 for any of the sample dates in 2006. Principle component 1 had a significant correlation with Hymenoptera species richness, although, its effect differed depending on the season. In spring 2005, principle component 1 had a negative correlation with Hymenoptera species richness (Figure 6; $\mathrm{p}=0.263 ; \mathrm{R}^{2}=0.15$ ). However, in summer 2005, principle component 1 had the opposite effect, and was positively associated with Hymenoptera species richness (Figure 6; $\mathrm{p}=0.015 ; \mathrm{R}^{2}=0.17$ ). Interestingly, there were no significant associations between Principle component 1 and Hymenoptera richness in any sample dates from 2006. 

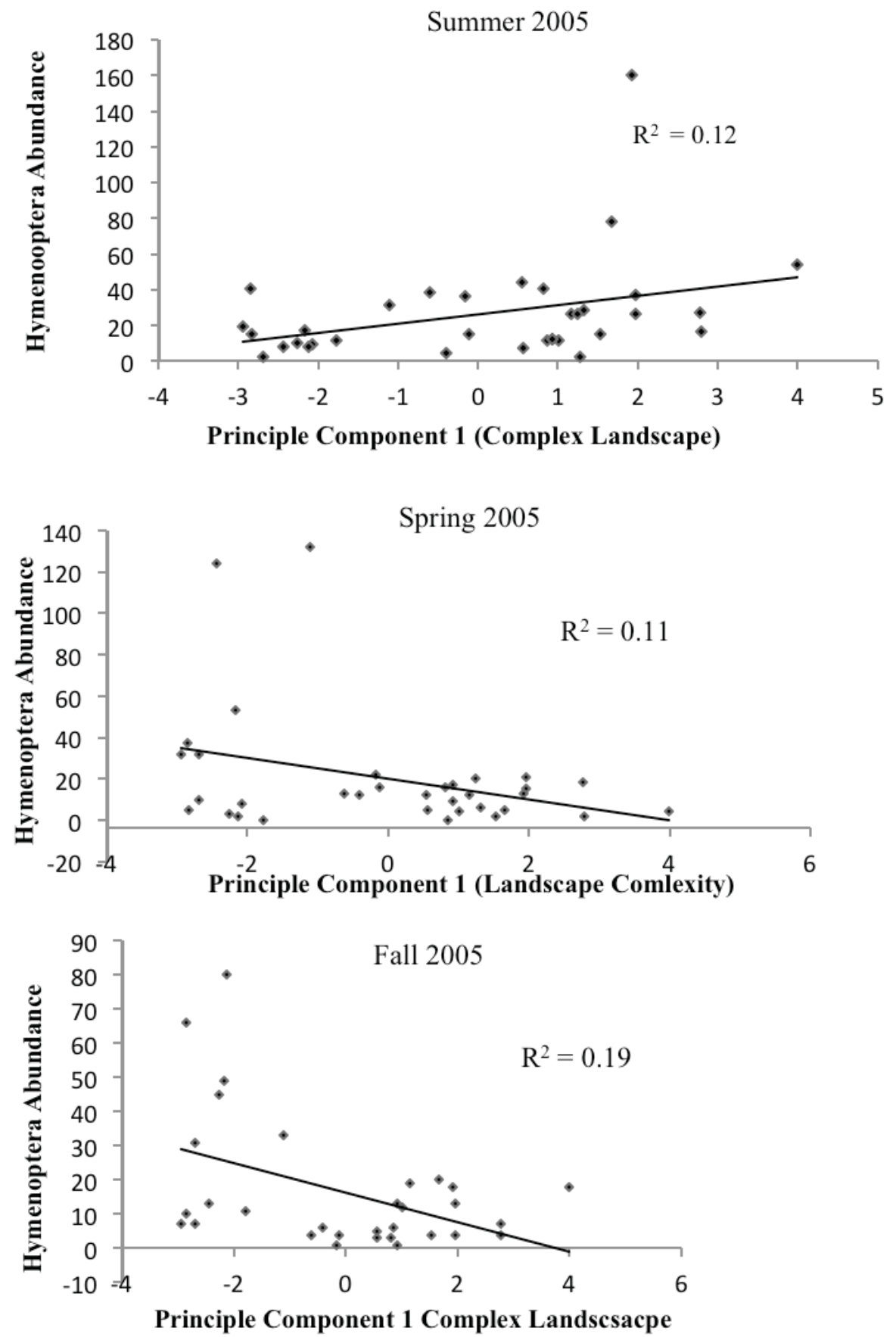

Figure 5. Principle Component 1 versus Mean Hymenoptera Abundance Spring, Summer, and Fall 2005 
Figure 5: Principle component 1 plotted against mean Hymenoptera abundance in spring, summer, and fall 2005. Principle component 1 is slightly negatively associated with Hymenoptera abundance in spring and fall of 2005. As principle component 1 increased, Hymenoptera abundance for spring and fall decreased $\left(p=0.065 ; R^{2}=0.11 ; p=0.012\right.$; $\mathrm{R}^{2}=0.19$ ). However, in summer 2005, principle component 1 had a positive with Hymenoptera abundance. As principle component 1 increased, Hymenoptera abundance for this sample period also increased $\left(p=0.042, R^{2}=0.12\right)$
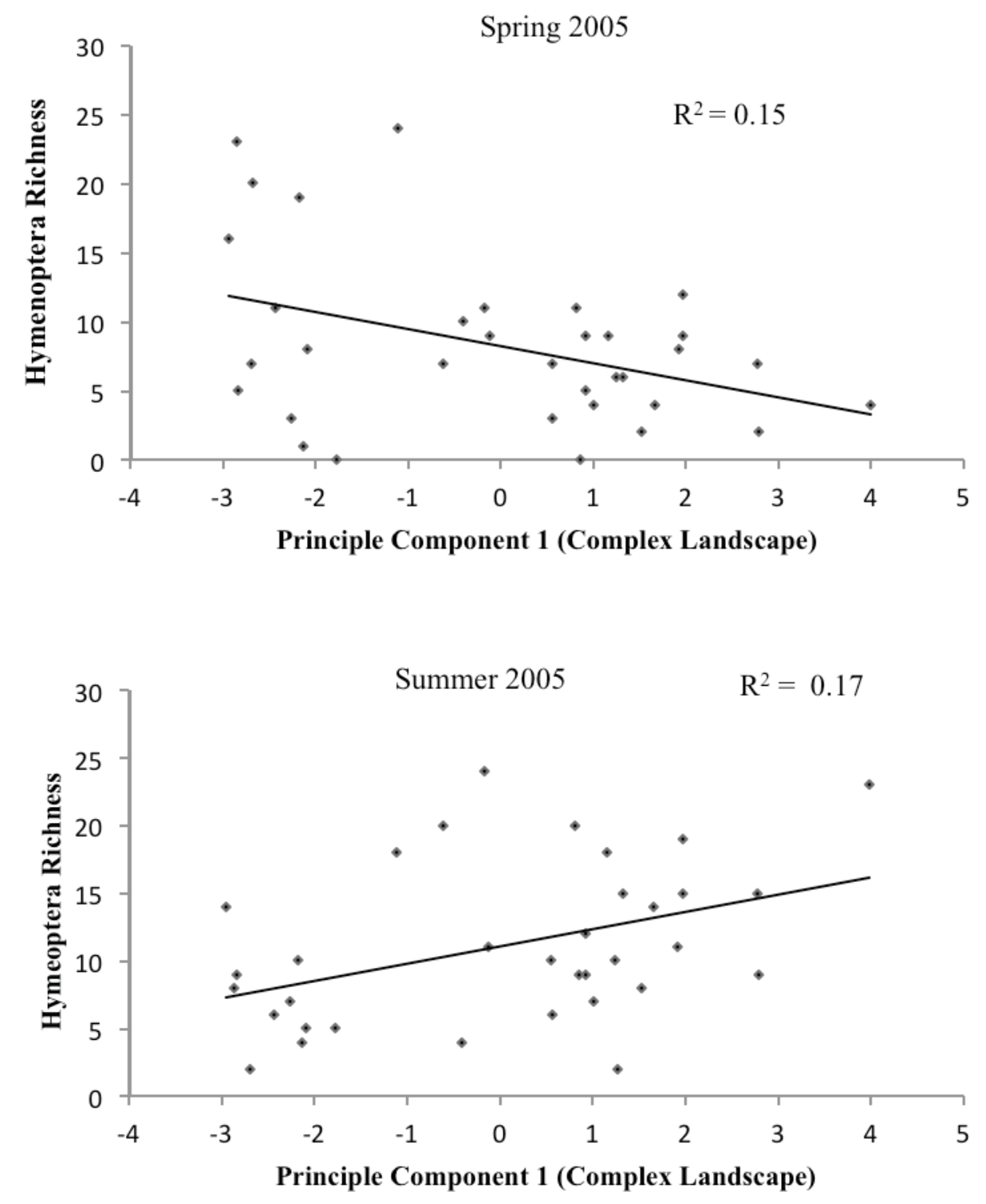

Figure 6. Principle Component 1 versus Mean Hymenoptera Richness Spring and Summer 2005 
Figure 6: Principle component 1 plotted against mean Hymenoptera species richness in spring and summer 2005. As principle component 1 increased, Hymenoptera richness in spring 2005 decreased $\left(p=0.026 ; \mathrm{R}^{2}=0.15\right)$. In the summer, however, as principle component 1 increased, mean Hymenoptera abundance increased ( $p=0.015 ; \mathrm{R}^{2}=0.17$ ).

Principle component 3. Principle component 3 (orchards, no grasslands) had a slight, but significant association with Hymenoptera species richness over all sample dates (Figure 7; $\mathrm{p}=0.026 ; \mathrm{R}^{2}=0.14$ ). Principle component 3 was also positively correlated with Hymenoptera abundance over all samples. As Principle component 3 increased, mean Hymenoptera abundance and richness over all the sample dates increased. Principle component 3 is a good predictor of mean Hymenoptera richness and abundance (Figure 7; $\mathrm{p}=0.002 ; \mathrm{R}^{2}=0.26$ ). 

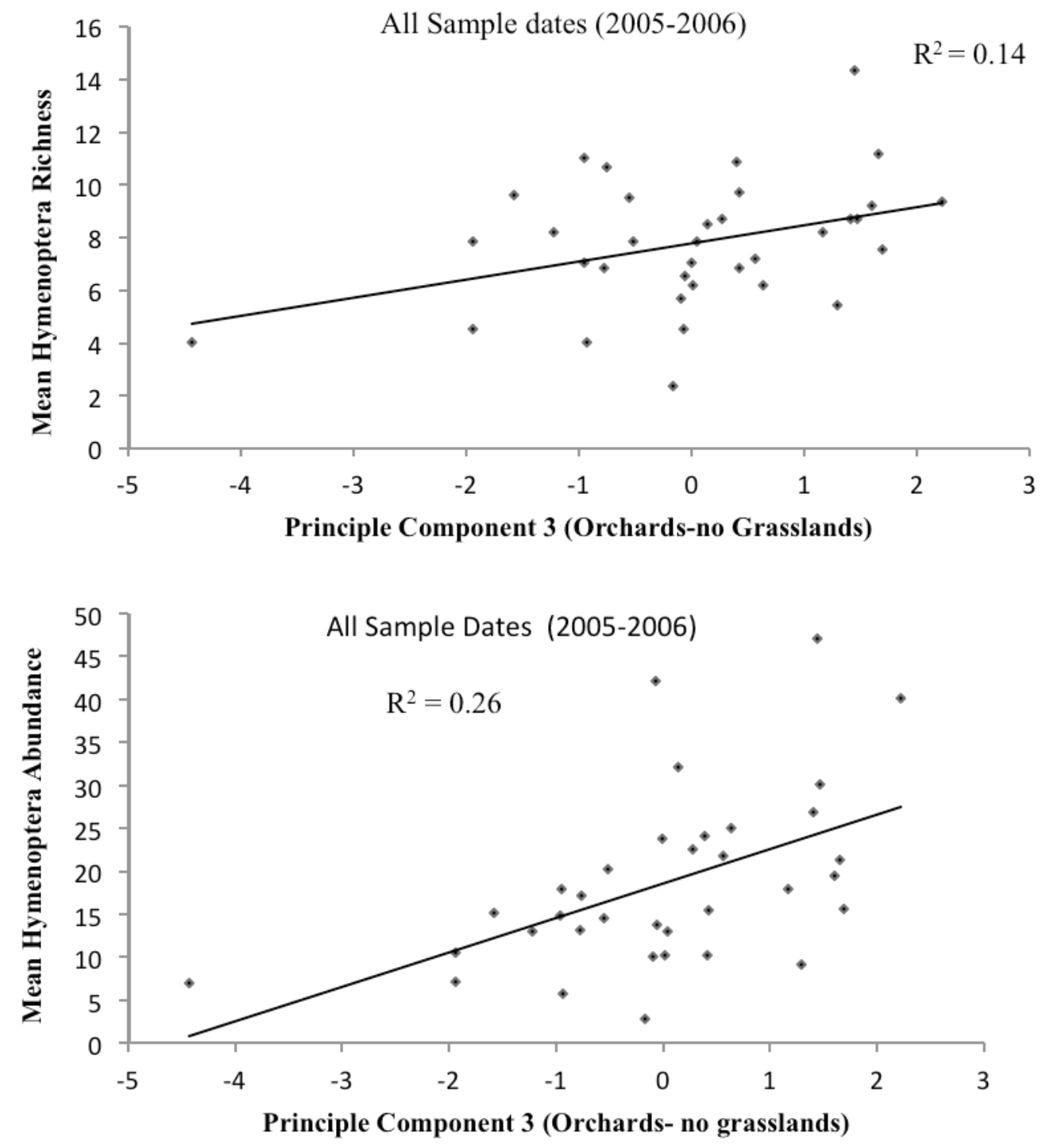

Figure 7. Principle Component 3 versus Hymenoptera Richness and Abundance Over All Sample Dates

Figure 7: Principle component 3 plotted against mean Hymenoptera richness and abundance over all sample dates. As principle component 3 increased, the mean richness and abundance of Hymenoptera over all sample dates increased $\left(\mathrm{p}\right.$-value $=0.026 ; \mathrm{R}^{2}=$ $\left.0.14 ; \mathrm{p}=0.002 ; \mathrm{R}^{2}=0.26\right)$. 
Grasslands. Plant richness had a varying relationship with Hymenoptera species richness. No consistent trends were identified, except in spring 2006. Hymenoptera species richness in spring 2006 was positively correlated with grasslands, or wild annual vegetation (Figure $8 ; \mathrm{p}=0.006 ; \mathrm{R}^{2}=0.21$ ). As the coverage percentage of grasslands increased within a 0.5-kilometer radius, Hymenoptera species richness increased as well.

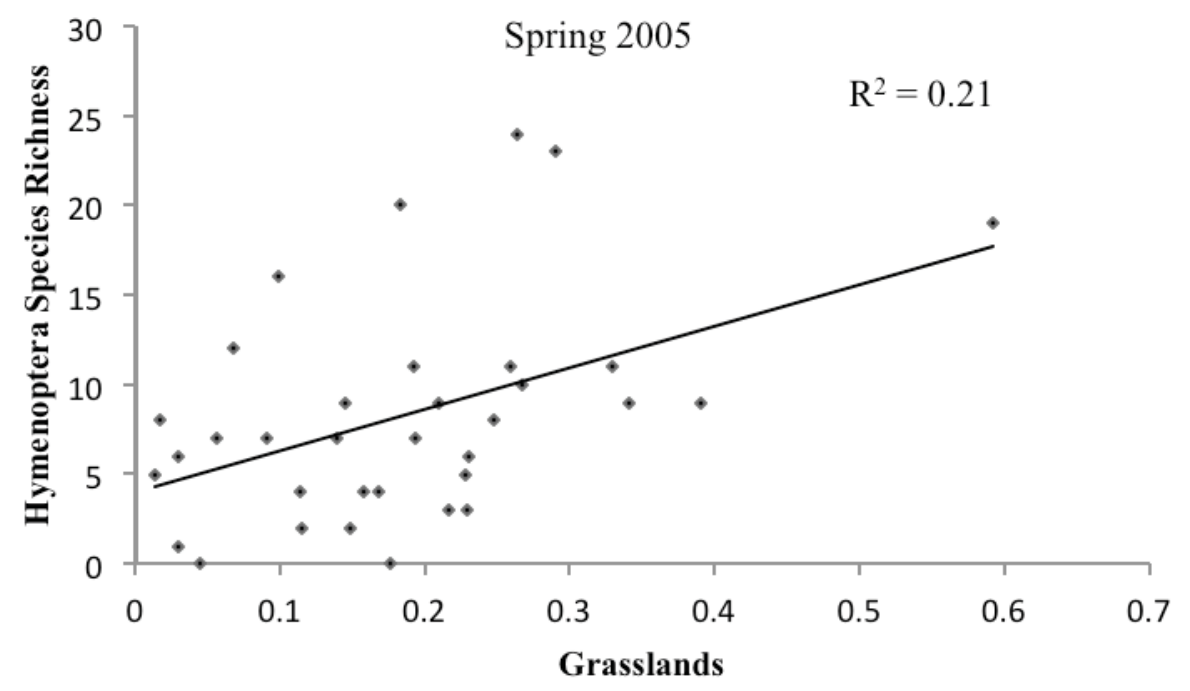

Figure 8. Grasslands versus Hymenoptera Richness Spring 2005

Figure 8: Grasslands plotted against Hymenoptera richness in spring 2005. As grasslands increased, Hymenoptera richness for this sample period increased $\left(p=0.006 ; R^{2}=0.21\right)$.

Non-crop species richness. Non-crop species richness for the first year of sampling, 2005, was negatively correlated with Hymenoptera abundance. Overall, Hymenoptera abundance for this year decreased as non-crop species richness increased (Figure 9; $\mathrm{p}=0.003 ; \mathrm{R}=0.24$ ). Spring 2006 supports this trend; non-crop species richness is negatively correlated with Hymenoptera richness. As non-crop species richness increased, Hymenoptera richness during this sample period decreased (Figure 
10; $\mathrm{p}=0.025 . \mathrm{R}^{2}=0.14$ ). There was no identifiable pattern between non-crop species richness and Hymenoptera richness over all sample dates; however, it should be noted that temporal variability was causing interesting seasonal trends.

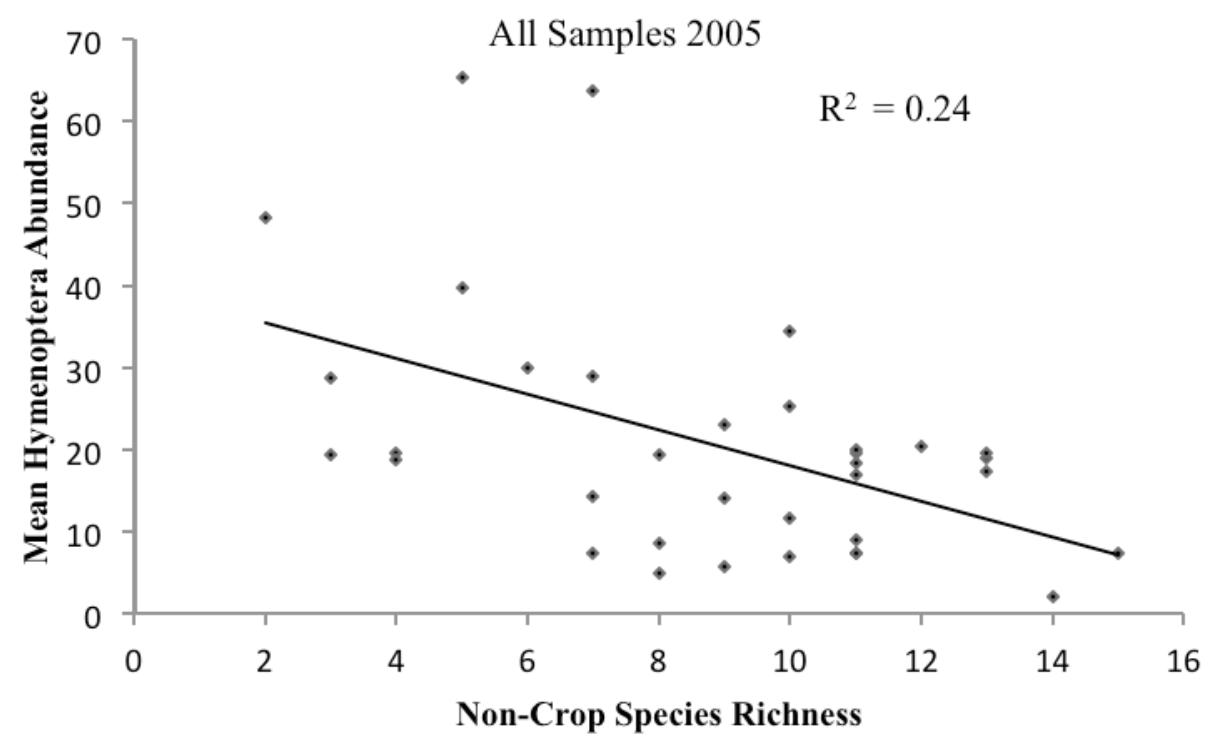

Figure 9. Non-Crop Species Richness versus Hymenoptera Abundance Over All Samples Dates from 2005

Figure 9: Non-crop species richness plotted against mean Hymenoptera abundance over all sample dates in 2005. Mean Hymenoptera abundance in 2005 correlates negatively with non-crop species richness. As non-crop species richness increased, Hymenoptera abundance decreased $\left(\mathrm{p}=0.003 ; \mathrm{R}^{2}=0.24\right)$. 


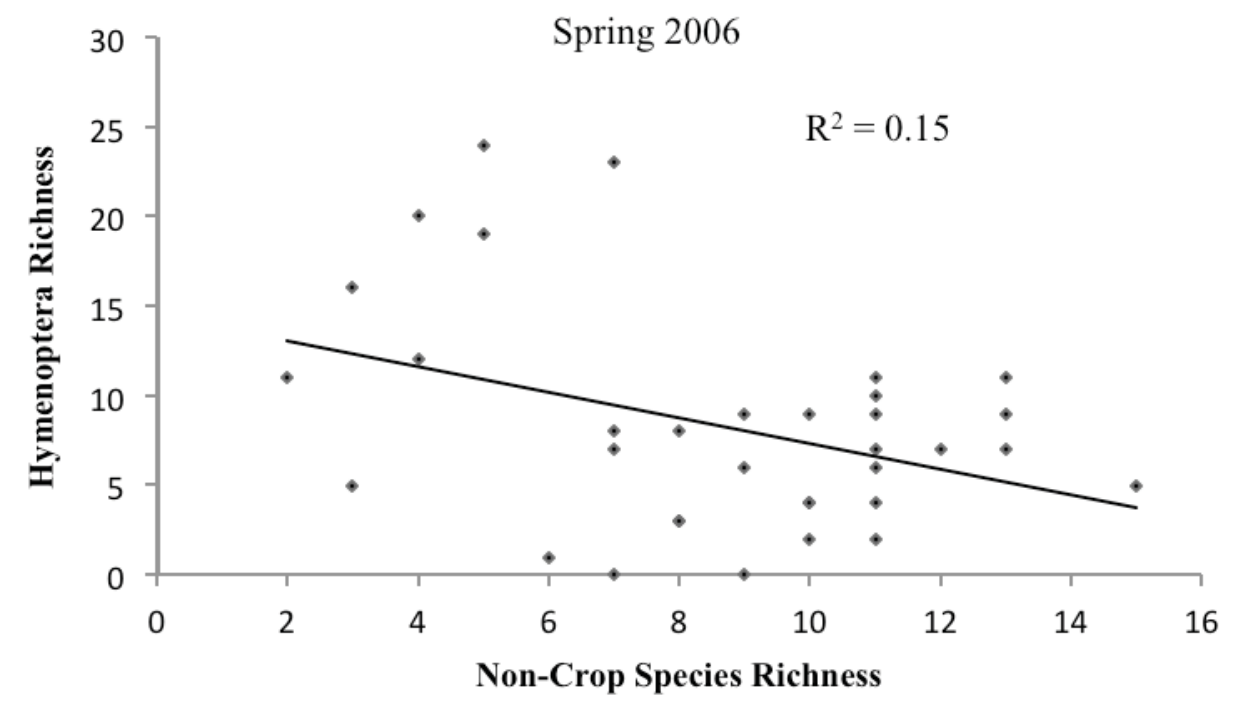

Figure 10. Non-crop Species Richness versus Hymenoptera Species Richness Spring 2006

Figure 10: Non-crop species richness plotted against Hymenoptera species richness in spring 2006. Non-crop species richness correlates negatively with Hymenoptera species richness. As the non-crop species richness increased, Hymenoptera species richness for samples collected in spring 2006 decreased $\left(\mathrm{p}=0.025 ; \mathrm{R}^{2}=0.15\right)$. 


\section{Farm-scale Biodiversity-H2a,b}

Data collection. The data were collected in September 2012.

Sampling process. The insect diversity of one heterogeneous field within Live Earth Farm was evaluated by placing modified elevated pan traps among crop rows throughout the field using the stratified random sampling method. The selected field was 461 meters long by 92 meters wide. Ten pan traps were interspersed in 38-meter sections, with a total of 12 sections and 120 pan traps placed randomly throughout the field. The pan traps were placed on stands made out of PVC pipes, which elevated them off the ground approximately 0.6 meters. The traps were white 113 -milliliter ceramic cups uniformly filled with 90 milliliters of soapy water to break the surface tension in the trap and keep the insects from flying out. Plant abundance and diversity were measured in a $30 \mathrm{~m}^{2}$ plot around each trap. Total plant species numbers and abundances were counted on every plot. Within each plot, a diameter of 1 meter was measured and the number of plants within that diameter noted. The total percentage cover of plants was also noted based on the approximate coverage of vegetation per plot.

Samples of plant species from each plot were collected and dried and placed in an herbarium. The traps were left in the field for a sampling period of 48 hours. The insects were collected 48 hours later with the help of twenty undergraduate field assistants from a San Jose State Sustainable Agriculture class. The pan traps were located throughout the field and the insects were then transferred in the field from the traps to 20-milliliter scintillation vials filled with ethanol by the students. This was done by straining the water out of the traps using a funnel, insect netting, and petri dishes. After the insects 
were collected and transferred into vials, they were transported to a laboratory at the University of California, Santa Cruz to be sorted and identified.

Data analysis. The insect specimens collected from the traps were examined using a dissection field AMScope microscope. The specimens from each subsample (insects collected from one elevated pan trap) were counted and for every vial, the abundance and richness was recorded. Insect abundance was obtained from counting all the specimens within each vial. Insect richness was identified by comparing key characteristics of each specimen and then sorting them out based on distinctive physiological features. Pictures of each taxonomic group were taken using a Leica DFC450 microscope camera with an optical lens model number Leica ZP6 APO. An AMScope microscope eyepiece camera MU500 was also used for taking pictures of the specimens. The richness of the most common taxonomic groups from each vial was identified to family. After the total abundance and richness was counted for every subsample, Microsoft Excel@ 2007 was used to obtain the total abundance by summing the total abundance and richness within every vial. The total percentage of non-crop cover was calculated in Excel@ 2007 as well. All the insect and plant data were organized in an Excel@ 2007 spreadsheet.

To interpret the results of the small-scale portion of this research, the following analytic methods were used:

Principal Components Analysis (PCA) was conducted using the software program SPSS $₫ 20$ to determine the patterns between on-farm vegetation and the abundance and diversity of insects. The independent variables measured were total plant species 
numbers, total percentage of plant cover, total percentage of non-crop cover, and the various crops in the field (Figure 4). The dependent variables measured included total insect abundance, total insect species richness, total Hymenoptera abundance and richness, and total Diptera abundance and richness. A linear regression was also conducted in SYSTAT $₫ 13$ to extrapolate the correlations between insect abundance and richness and the diversity of plant vegetation in the field. Both the independent and the dependent variables used in the regression were the same variables used in the PCA.

Outcomes. A total of 3,032 specimens were collected with 27 common morphospecies identified to either family or superfamily. Diptera made up the majority of the specimens analyzed, accounting for $31 \%$ of the total, while Thysanoptera made up $39.5 \%$ of the total abundance. Hymenoptera represented $4.6 \%$ of the total morphospecies analyzed and included parasitoid wasps. The remaining $24.9 \%$ comprised other major taxonomic groups including Coleoptera, Lepidoptera, Orthoptera, Hemiptera, and Neuroptera (Table 5). 
Table 5: Common Insect Morphospecies from Live Earth Farm

\begin{tabular}{|l|l|l|l|l|l|}
\hline Order & & & & & \\
& Superfamily & Family & Name & & \\
Diptera & Ephydroidea & Drosophilidae & Fruit Fly & Fruit Feeders & 878 \\
\hline Diptera & Chironomoidea & Chironomidae & Midge & $\begin{array}{l}\text { Blood } \\
\text { feeders }\end{array}$ & 48 \\
\hline Thysanoptera & unknown & unknown & Thrips & Herbivore & 1200 \\
\hline Orthoptera & unkown & unkown & $\begin{array}{l}\text { Grasshoppe } \\
\text { r }\end{array}$ & Herbivore & 3 \\
\hline Lepidoptera & unknown & unknown & Moth & Herbivore & 2 \\
\hline Lepidoptera & unknown & unknown & Butterfly & Herbivore & 1 \\
\hline Lepidoptera & unknown & unknown & Caterpillar & Herbivore & 9 \\
\hline Araneae & unknown & unknown & Spider & Predator & 14 \\
\hline Coleoptera & Chrysomeloidea & Chrysomelidae & $\begin{array}{l}\text { Spotted } \\
\text { Cucumber } \\
\text { Beetle }\end{array}$ & Herbivore & 14 \\
\hline Coleoptera & Tenebrionoidea & Anthicidae & $\begin{array}{l}\text { Ant-like } \\
\text { Flower } \\
\text { Beetle }\end{array}$ & Predator & 2 \\
\hline Hemiptera & unknown & Anthocoridae & $\begin{array}{l}\text { Minute } \\
\text { Pirate Bug }\end{array}$ & Predator & 35 \\
\hline Hemiptera & Lygaeoidea & Lygaeidae & $\begin{array}{l}\text { Brown Seed } \\
\text { Bug }\end{array}$ & Seed Feeders & 22 \\
\hline Hemiptera & Aphidoidea & unknown & Aphid & Herbivore & 45 \\
\hline Hymenoptera & Apoidea & unknown & Bee & Pollinator & 97 \\
\hline Hymenoptera & Chalcidoidea & Pteromalidae 1 & Chalcid A & Parasitoid & 1 \\
\hline Hymenoptera & Chalcidoidea & Pteromalidae 2 & Chalcid B & Parasitoid & 5 \\
\hline Hymenoptera & Chalcidoidea & Pteromalidae 3 & Chalcid C & Parasitoid & 1 \\
\hline Hymenoptera & Chalcidoidea & Pteromalidae & Chalcid D & Parasitoid & 1 \\
\hline Hymenoptera & Ichneumonoidea & Braconidea & $\begin{array}{l}\text { Braconid } \\
\text { wasp }\end{array}$ & Parasitoid & 4 \\
\hline Hymenoptera & Vespoidea & Vespidae & $\begin{array}{l}\text { Yellow } \\
\text { Jacket }\end{array}$ & Predator & 30 \\
\hline Hymenoptera & Vespoidea & Pompilidae & $\begin{array}{l}\text { Spider } \\
\text { Wasp }\end{array}$ & Parasitoid & 21 \\
\hline Neuroptera & Chrysopoidea & Chrysopidae & Lacewing & Predator & 1 \\
\hline & & & & \\
\hline
\end{tabular}


Principle components. Five principle components were used for this analysis. Principle component 1 was made up of overall non-crop cover, total plant cover, different plant species, and peppers. Hence, principle component 1 is essentially overall plant cover (weeds) and peppers. Principle component 2 was made up of clean tomatoes.

Principle component 1. Principle component 1 (peppers and non-crop cover) had a significant positive correlation with overall insect species abundance. As principle component 1 increased, overall insect species abundance increased per $\sim 30 \mathrm{~m}^{2}$ plot (Figure 11; $\mathrm{R}^{2}=0.29 ; \mathrm{p}=0.000$ ). Principle component 1 also had a significant positive correlation with overall Diptera species abundance. As principle component 1 increased, Diptera abundance also increased per plot (Figure 11; $\mathrm{R}^{2}=0.19 ; \mathrm{p}=0.000$ ).

Principle component 1 also had a significant positive correlation with overall insect species richness. As principle component 1 increased, overall insect species richness increased per $\sim 30 \mathrm{~m}^{2}$ plot (Figure 12; $\mathrm{R}^{2}=0.33 ; \mathrm{p}=0.000$ ). Principle component 1 also had a significant positive correlation with overall Diptera species richness. As principle component 1 increased, Diptera species richness also increased per plot (Figure $\left.12 ; \mathrm{R}^{2}=0.27 \mathrm{p}=0.000\right)$. 

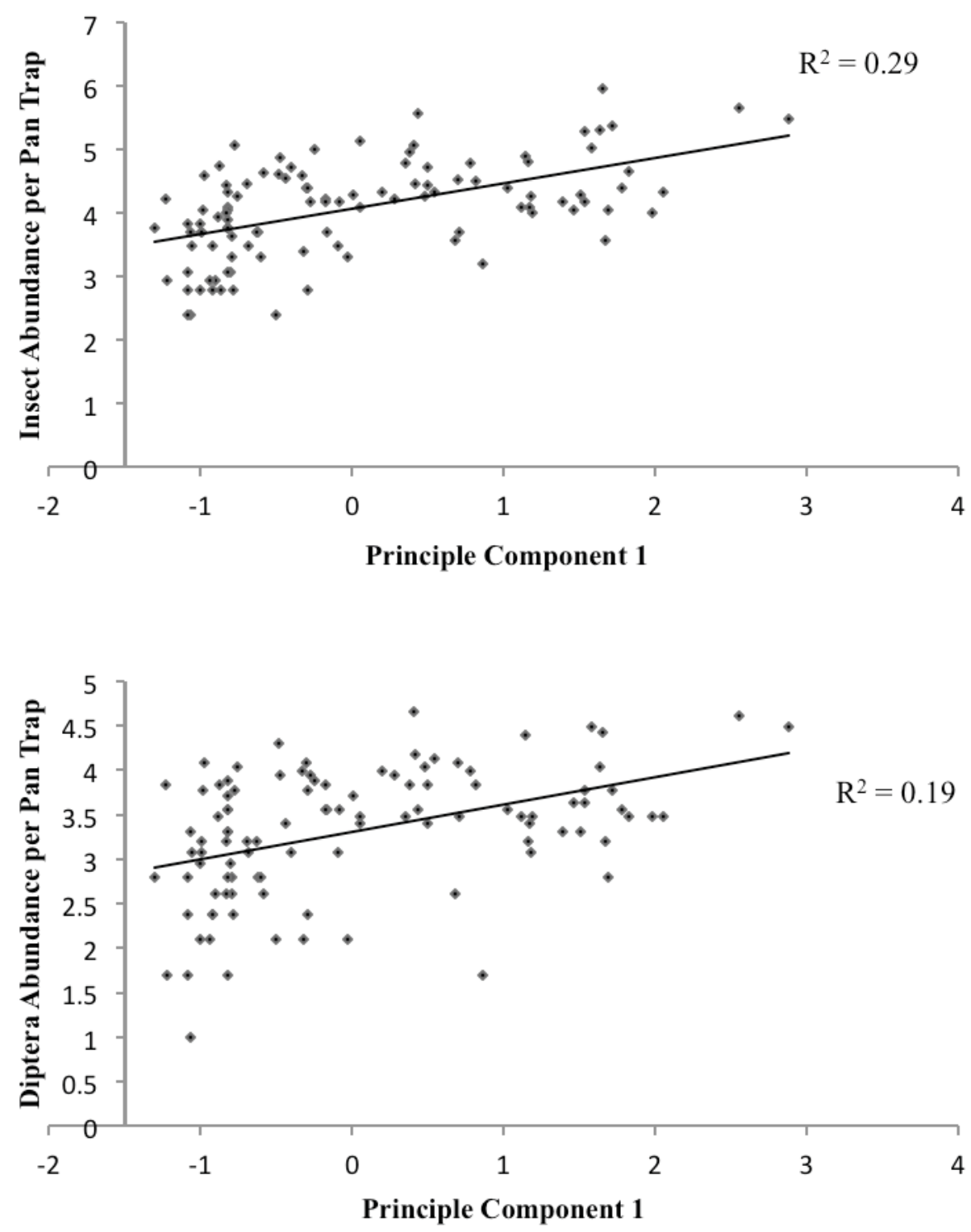

Figure 11. Principle Component 1 versus Insect Abundance

Figure 11: As principle component 1 (peppers and non-crop cover) increased, total insect abundance increased $\left(p=0.00 ; R^{2}=0.29\right)$ with Diptera comprising a measurable fraction of the whole $\left(p=0.00 ; R^{2}=0.19\right)$. 

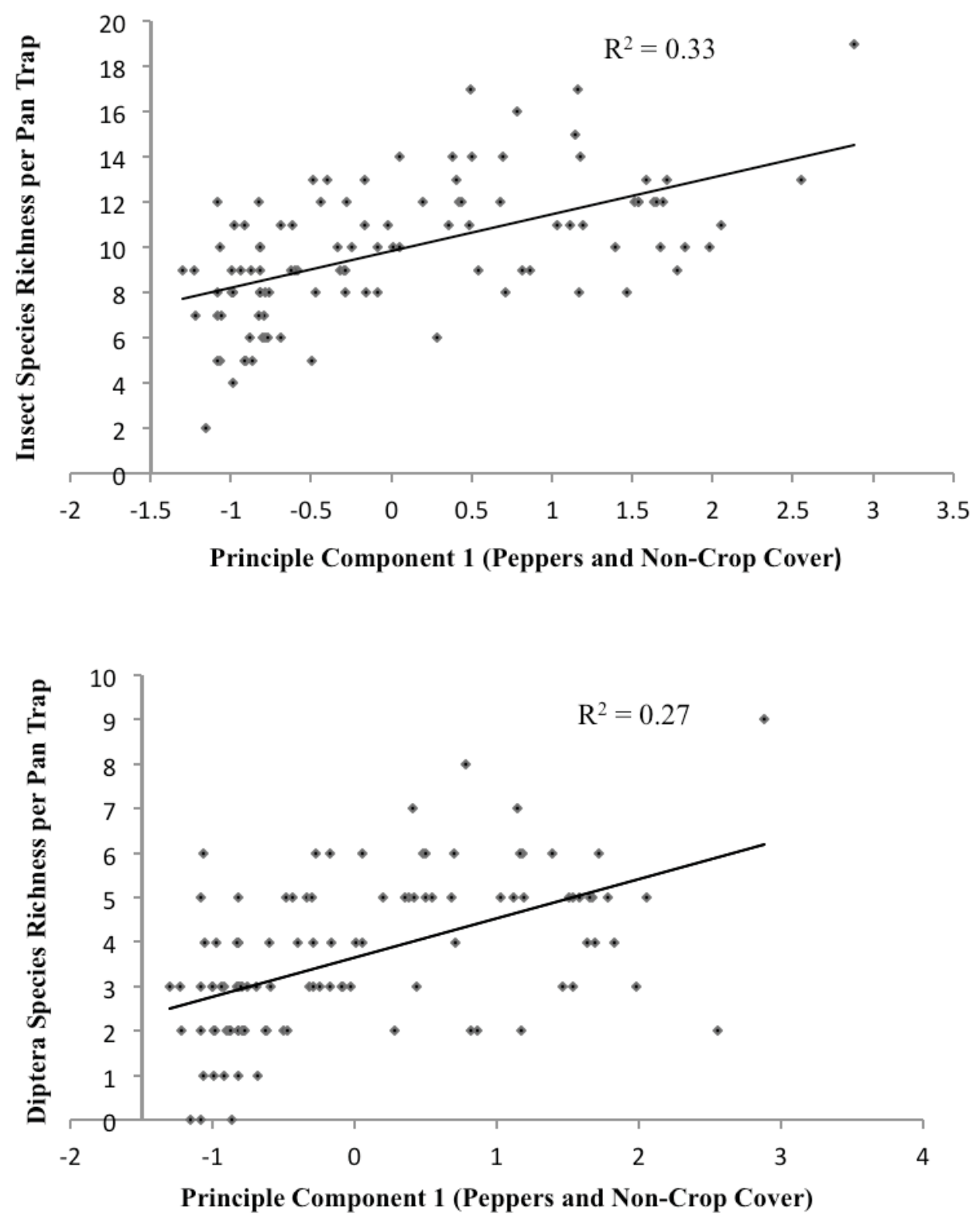

Figure 12. Principle Component 1 versus Insect Species Richness

Figure 12: Overall insect species richness plotted against principle component 1. Principle component 1 is positively associated with overall insect species richness $(\mathrm{p}=$ $\left.0.000 ; R^{2}=0.33\right)$, with Diptera diversity paralleling the overall pattern $\left(p=0.000 ; R^{2}=\right.$ $0.27)$. 
Principle component 2. Principle component 2 (clean tomatoes), however, had a negative association with overall insect abundance. As principle component 2 increased, overall insect abundance decreased (Figure 13; $\mathrm{p}=0.007 ; \mathrm{R}^{2}=0.07$ ). Overall Diptera abundance was also negatively associated with principle Component 2. As principle component 2 increased, Diptera abundance also decreased (Figure 13; $\mathrm{p}=0.00 ; \mathrm{R}^{2}=$ $0.13)$.

Principle component 2 was negatively associated with overall insect species richness. As principle component 2 increased, overall insect species richness decreased (Figure 14; $\mathrm{R}^{2}=0.09 ; \mathrm{p}=0.002$ ). Principle component 2 was also negatively associated with overall Diptera species richness. As principle component 2 increased, Diptera species richness decreased (Figure 14; $\mathrm{R}^{2}=0.09 ; \mathrm{p}=0.002$ ). 

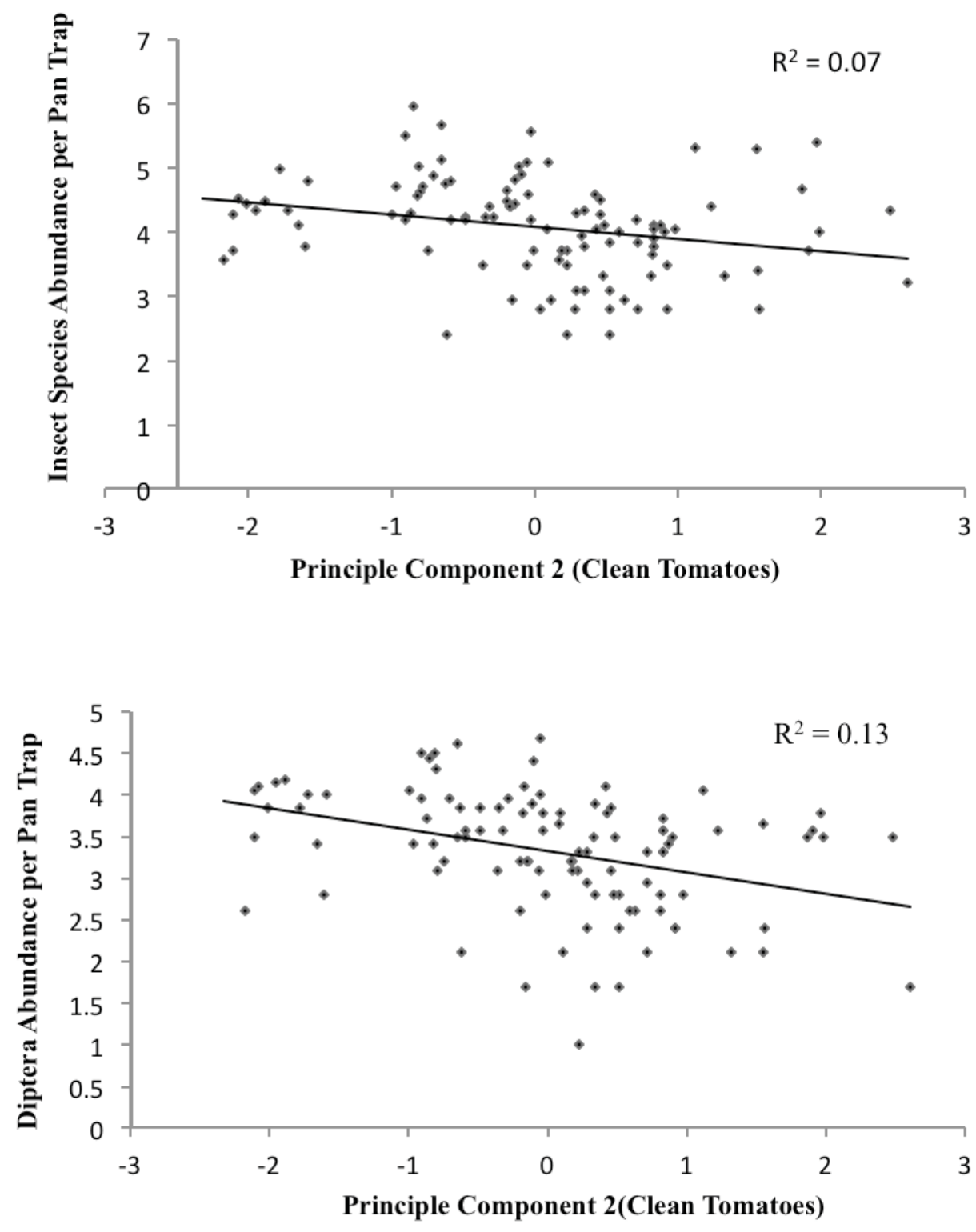

Figure 13. Principle Component 2 versus Insect Abundance

Figure 13: As principle component 2 increased, overall insect abundance decreased ( $\mathrm{p}=$ 0.007; $\left.\mathrm{R}^{2}=0.07\right)$, as do flies (Diptera) in particular $\left(\mathrm{p}=0.00 ; \mathrm{R}^{2}=0.13\right.$ ). 

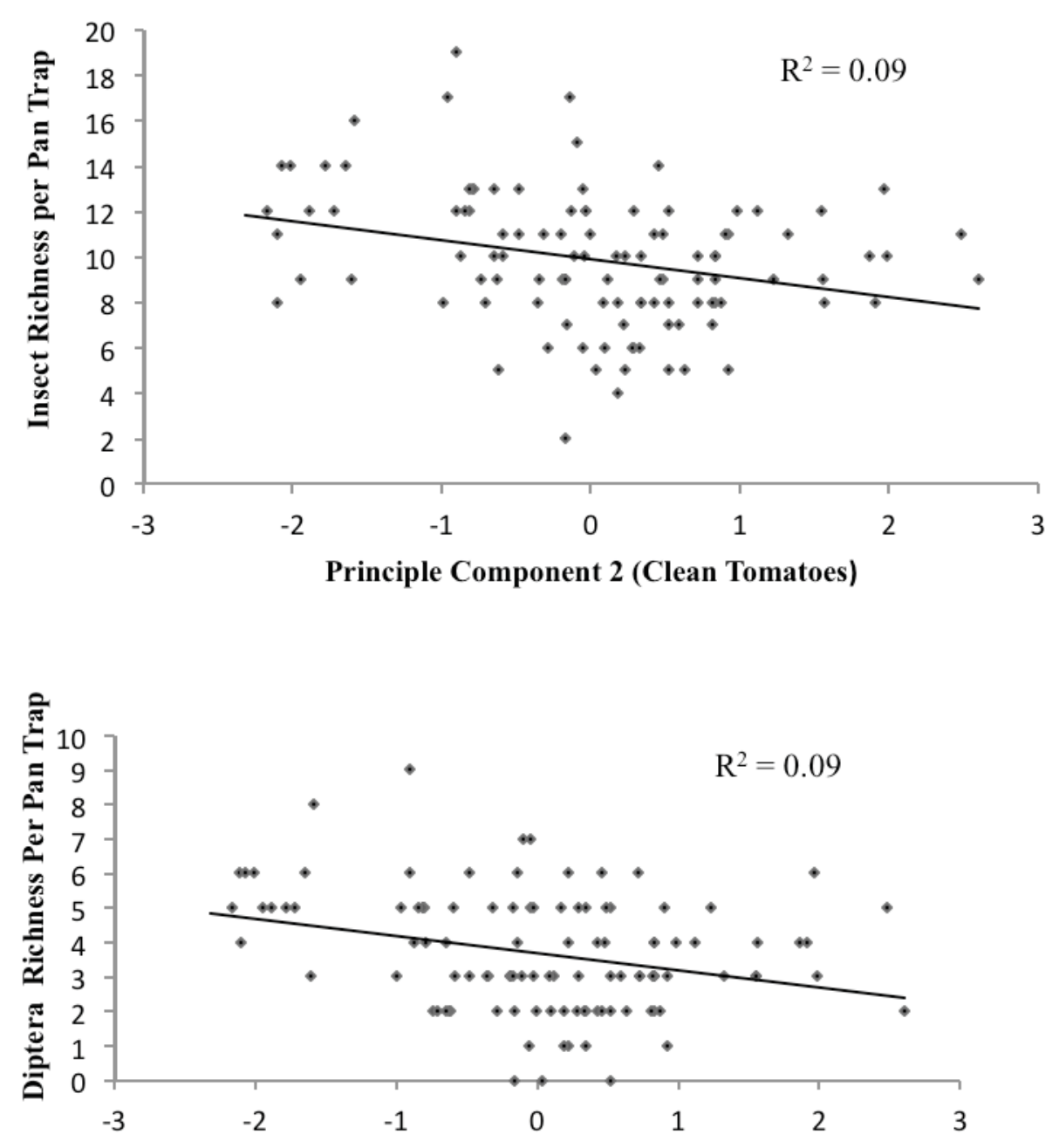

Principle Component 2 (Clean Tomatoes)

Figure 14. Principle Component 2 versus Insect Species Richness

Figure 14: Principle component 2 plotted against insect species richness. Principle component 2 is correlated negatively with insect species richness, including Diptera. As principle component 2 increased, overall insect species richness decreased $\left(\mathrm{p}=0.002 ; \mathrm{R}^{2}\right.$; 0.09; $\mathrm{p}=0.002 ; \mathrm{R}^{2}=0.09$ ).

Non-crop cover. The percentage of non-crop cover per plot was positively associated with insect species abundance. Interestingly, plant species diversity was not a 
driving factor affecting insect abundance. Mean insect abundance showed a positive correlation with the percentage of non-crop cover (Figure 15; $\mathrm{p}=0.000 ; \mathrm{R}^{2}=0.35$ ). Non-crop cover was also positively associated with insect species richness. Mean insect abundance showed a positive correlation with the percentage of non-crop cover (Figure 16; $\mathrm{p}=0.000 ; \mathrm{R} 2=0.37$ ). Diptera richness was also positively correlated with non-crop cover and appears to be a major factor driving this trend (Figure 16; $\mathrm{p}=0.000$; $\left.\mathrm{R}^{2}=0.29\right)$. Hymenoptera abundance was also measured against percent non-crop cover; however, for this analysis the bees were removed due to their sporadic presence throughout the samples. The mean Hymenoptera abundance without bees, only wasps, showed a positive correlation with the percentage of non-crop cover per plot; however, a small sample size resulted in high background variability (Figure 16; $\mathrm{p}=0.000 ; \mathrm{R}^{2}=$ 0.08). Larger sample sizes are needed to validate this association, but even with a small sample size, the positive correlation between Hymenoptera wasp abundance and plant cover and richness is still evident. 


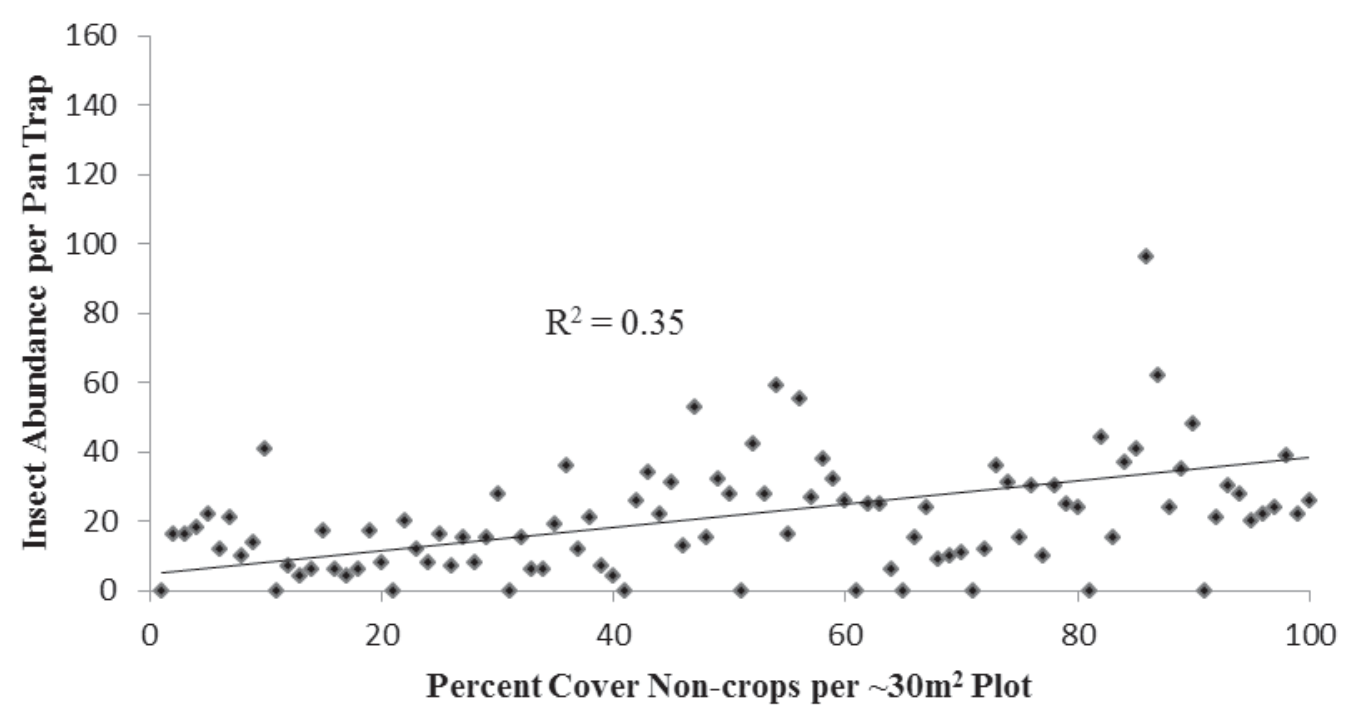

Figure 15. Non-crop Cover versus Insect Abundance

Figure 15: Mean insect abundance plotted against percentage non-crop cover. Insect abundance correlates positively with percentage non-crop cover per plot in particular. As the total percentage of non-crop cover increased, insect abundance was positively affected ( $\left.\mathrm{p}=0.000 ; \mathrm{R}^{2}=0.35\right)$. 

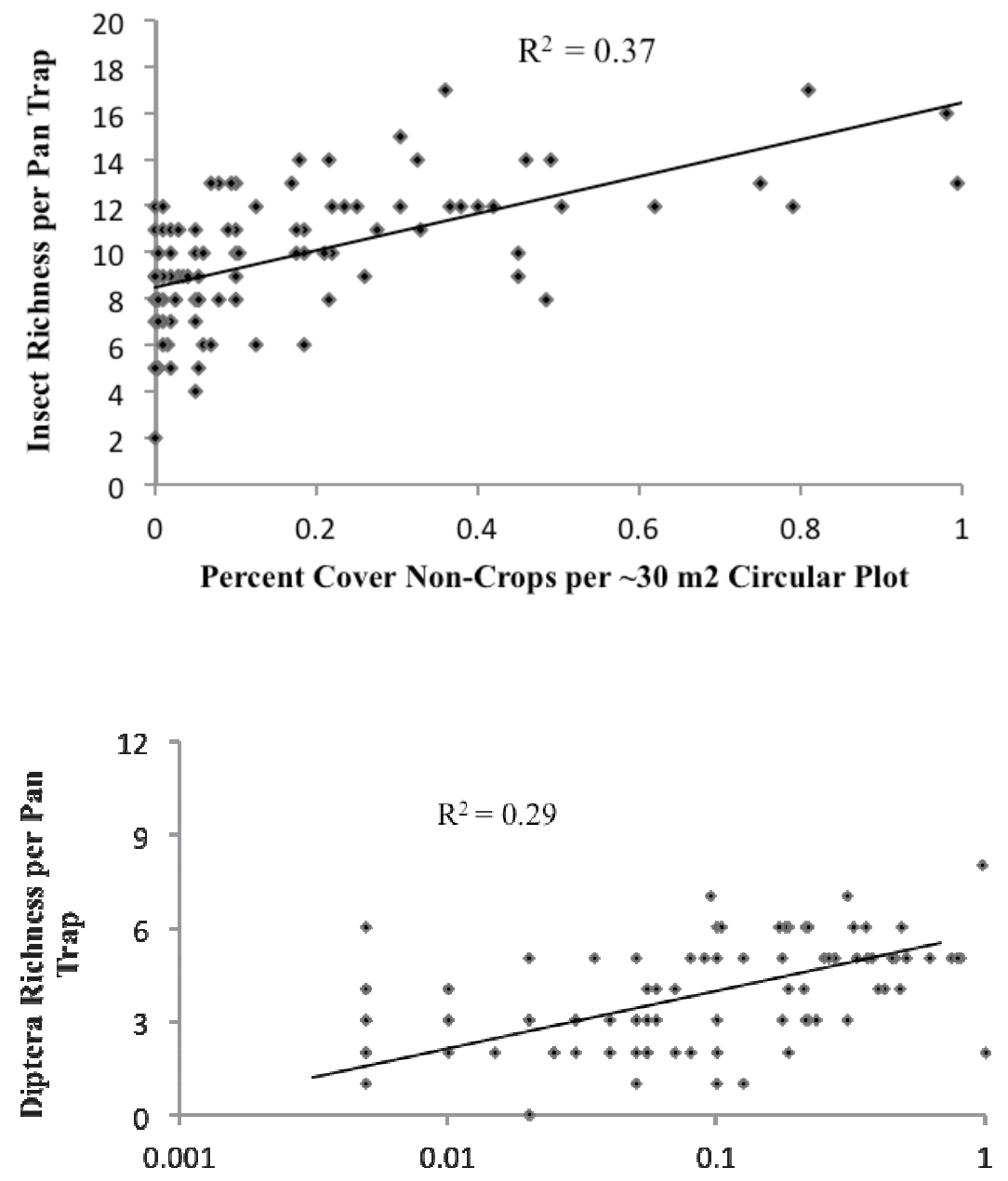

Percent Cover Non-crops per $\sim \mathbf{3 0 m 2}$ Circular Plot

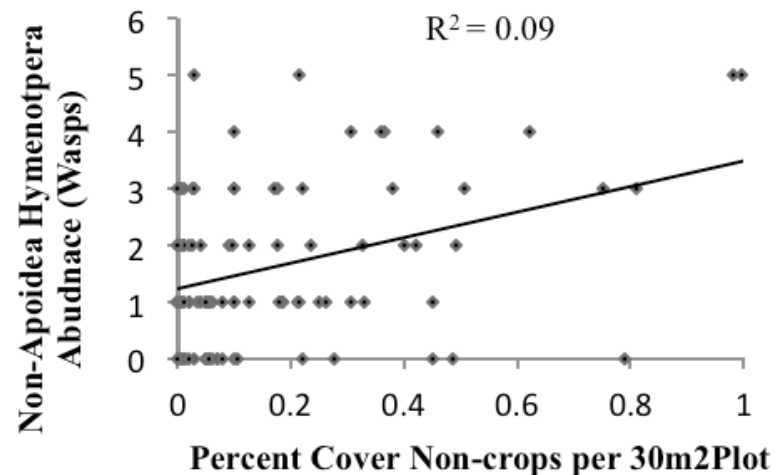

Figure 16. Non-crop Cover versus Insect Species Richness 
Figure 16: Mean insect species richness plotted against percentage of non-crop cover. Insect species richness, including Diptera and wasps, correlates positively with percentage of crop cover per plot. As the total percentage of non-crop cover increased, insect species richness was positively affected. Diptera species richness was driving the positive increase with non-crop cover, while Hymenoptera (without the bees) was also an important factor in the positive association between non-crop cover and insect species richness ( $\mathrm{p}=0.00 ; \mathrm{R}^{2}=0.37 ; \mathrm{p}=0.00 ; \mathrm{R}^{2}=0.29 ; \mathrm{p}=0.002 ; \mathrm{R}^{2}=0.09$ ).

Table 6: Overview of Farm-scale Results

\begin{tabular}{|c|c|c|c|c|c|c|}
\hline \multirow[b]{2}{*}{ Farm Scale Results } & \multicolumn{2}{|c|}{ All Insects } & \multicolumn{2}{|c|}{ Diptera (Flies) } & \multicolumn{2}{|c|}{$\begin{array}{l}\text { Hymenoptera } \\
\text { (only wasps) }\end{array}$} \\
\hline & 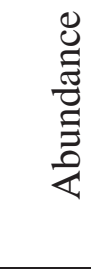 & 号 & 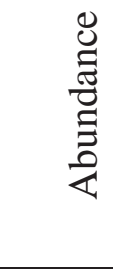 & 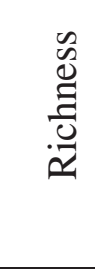 & 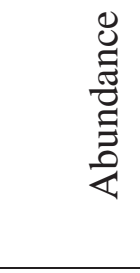 & 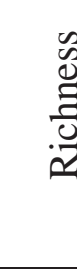 \\
\hline $\begin{array}{l}\text { PC1(total plant cover and } \\
\text { peppers) }\end{array}$ & + & + & + & + & $\varnothing$ & $\varnothing$ \\
\hline PC2(tomatoes no weeds) & - & - & - & - & $\varnothing$ & $\varnothing$ \\
\hline Percent Cover Non-crops & + & + & $\varnothing$ & + & + & + \\
\hline
\end{tabular}




\section{Discussion}

The results of this study highlight the importance, as well as the complexities, of the "landscape matrix" in understanding the multifaceted but essential ways vegetation impacts insect diversity. Beginning with the landscape-scale portion of the study, it is important to look at the overarching findings in the context of Letourneau et al. (2012). In their study, tachinid flies increased with wild perennial vegetation across all the sampling dates. The fact that Hymenoptera increased in this study only in the summer as vegetation in the surrounding landscape increased, but decreased in spring and fall, showing temporal and seasonal variation, suggests factors such as host specificity affect the tachinids and Hymenoptera differently. The majority of tachinids are generalist parasitoids, whereas many Hymenopteran parasitoids are considered specialist parasitoids. These parasitoids may migrate out of the fields in the spring and fall when conditions are less than optimal for their feeding needs due to a possible decrease in their host taxa.

Spring is the time when native perennial plants outside the fields are in full bloom, providing abundant resources, including host plants and host species for the Hymenopteran parasitoids. The season that produced positive correlations in the farm fields between Hymenoptera abundance and richness and vegetation was summer, when agricultural lands are in full production. Summer also has fewer disturbances, such as tilling, providing a season of refugia with fewer anthropogenic disruptions. One hypothesis is that more specialized Hymenopteran natural enemies migrate into the fields in the summer when conditions are the most optimal and then leave the fields in the 
spring and fall when native grasses and other plants die off and more on-farm disturbances occur.

However, Letourneau et al. (2012) found that the more generalist tachinid species were more prone to switch between habitats, especially host taxa migrating from dry surrounding landscapes after summer to irrigated crop fields in the fall. This could then mean some morphospecies of Hymenoptera in this study are generalists, causing them to migrate between habitats. Another possible explanation for the negative correlation of Hymenoptera with semi-wild perennial vegetation in the spring and fall could be the connectivity and the high quality of habitats surrounding the farms. Embedded within fragmented mosaics of complex landscapes surrounded by highly connected patches of crop-non-crop cover, Hymenoptera may have migrated to the surrounding landscapes in the spring and fall rather than remaining in the center of the crop field.

Because of the heterogeneity of the farms used in the study in terms of scale, vegetation, and temporal variation, both insect richness and abundances fluctuated. This interesting trend in temporal variation could be occurring due to the quality of the habitats and the environmental variability on the farms associated with the changing seasons.

The positive association between Hymenoptera abundance and richness with orchards and crop diversity over all sampling dates (principle component 3) is an interesting and complex element to the landscape-scale part of this study. It suggests orchards play a special role in agricultural landscapes. When annual grasses and forbs die out in the spring and fall, Hymenopteran parasitoids may take refuge in orchard 
systems with a mixture of crops and other plants. These Hymenopteran taxa may remain in these orchards in the summer, as they have all the resources they need. Also, agroecosystems with complex surrounding landscapes that have well-connected early and late successional habitats are stable ecosystems that promote resilience from both largeand small-scale disturbances. Hymenoptera species inhabiting the ecosystems sampled in this study may be sustaining their populations through migrating into non-crop habitats in the surrounding landscape matrices. These non-crop habitats also provide a source of generalist host species migrating into the crop area, thus increasing the potential for pollination or biological control (Tscharntke et al. 2005).

The farm scale part of this study, at Live Earth Farm, produced results supporting the literature that shows the complex agroecosystems have more insect diversity than simple agricultural landscapes (Andow 1991, Root 1973, Letourneau et al. 2011). As non-crop species increased in the field, insect abundance and richness increased. These results are consistent with those of other studies on biological control and natural enemies and support the prediction that farms with more complex levels of on-farm vegetation can enhance the biodiversity of beneficial insects, such as Hymenopteran parasitoids.

One of the taxonomic groups that responded to increases in non-crop cover in the field was Diptera, or flies. Having a diversity of flies in the field helps maintain the balance and vitality of the ecosystem. As previously mentioned, many species of fly are beneficial pollinators as well as predatory parasitoids (Tooker et al. 2006). In supporting a large richness of flies, agroecosystems also help prevent major pest outbreaks and diseases. The small-scale portion of this study highlights the importance of having 
richness or diversity as well as abundances of insects in the field. Species richness in agroecosystems is important for top-down control, as diversity of predators and parasitoids is an essential element in the functionality of ecosystems. Species richness is important in agroecosystems, as natural enemy diversity on farms has been shown to result in higher herbivore suppression (Letourneau et al. 2009). Insect abundance is also a crucial element to the stability of agricultural landscapes and provides a bottom-up method of control. Insect abundance is important in biological control, providing an important source of food for other organisms in the community, thus providing ecosystem stability.

The results at the landscape level have more complexities and inconsistences between vegetation and insect abundance and richness than those at the smaller on-farm scale. To successfully create agroecosystems comprising a diversity of both generalist and specialist natural enemies, it is necessary to understand the connections, interactions, and complexities between the landscape-scale and the smaller farm-scales. This study points to the inconsistencies between the scales and the need for future studies to continuously analyze both scales in order to understand how insects are affected by surrounding vegetation and the interactions of taxa among these fragmented agroecosystems.

These results point to the importance of maintaining vegetation diversity on and around farms, as increased vegetation on these agricultural landscapes constitutes an important habitat for insects. Having more vegetation cover on and around farms counteracts many negative environmental consequences of industrialized agriculture. For 
example, increased plant cover on and around fields helps prevent wind and water erosion, a common consequence of monoculture farms. Simple agricultural landscapes with little plant diversity create erosion, which causes an increase in sedimentation in lakes and rivers that can have devastating effects on aquatic organisms (Matson et al. 1997). Many of the farms in this study have non-crop vegetation in and around crop fields, which has been shown to help reduce water pollution. Having vegetation barriers or buffer strips on or along the edges of fields facilitates sedimentation and reduces the transport of harmful water contaminants (Stuart et al. 2006). Complex agricultural landscapes with a diversity of vegetation provide habitats for species biodiversity, both vertebrate and invertebrate, and stabilizing and protecting these sensitive environments from the environmental consequences of modern industrialized agriculture.

According to Tscharntke and Brandl (2004), understanding local and community processes that take place across the mosaics of fragmented agricultural landscapes requires understanding the myriad components of landscape matrices. The authors note that understanding the intricate and dynamic interactions between these spatial scales will require a more extensive perspective in population and community ecology. The new conservation paradigm must acknowledge the role landscape matrices and their surrounding vegetation play in maintaining the biodiversity in agroecosystems. The results of this study validate the importance of Tscharntke and Brandl's assertions of the importance of understanding the complexities of the landscape matrices and incorporating our knowledge of different scales into ecological practices. 


\section{Recommendations}

This study points to the complexities of insect patterns and movements in agricultural landscapes in connection with vegetation in the surrounding landscapes. Due to inconsistencies and sometimes unclear patterns, it is important future studies continue to look at how plant vegetation affects insects, especially at multiple scales. Future studies should focus on large landscape-level scales in tandem with smaller on-farm scales, across multiple seasons. The small on-farm-scale portion of this study was conducted in only one season, fall. It is important future studies conduct on-farm studies but across multiple seasons and multiple years. This study showed temporal and seasonal variations are factors that play a role in insect migration; future studies must continue to look at these important issues across multiple years and seasons.

Future ecological studies must focus on landscape-scale research on more taxa and across more seasons to fully understand how natural enemies and parasitoids use managed agricultural landscapes as refuges. The surrounding vegetation and the different stages of farm seasons affect the life cycles and migration patterns of these taxa in complex ways, and more studies must be done to further validate the results of present research. It is also important to pay attention to the surrounding vegetation and to sample often in order to be aware of when insects move into the fields and whether they are suppressing pests nearby. Although numerous studies assess how the complexities of vegetation in fragmented agroecosystems affect insects, many questions still remain unanswered. 
This study underscores the value that farmers should place on insects in their fields. The non-crop plants - the "weeds" - can be valuable not only to bats and birds but to parasitoids and other beneficial insects. Farmers across the Central Coast should consider leaving more weedy borders and covering their soil with a wide variety of plant vegetation that provides habitats and refuge for beneficial insects such as parasitoid wasps that migrate throughout the farm fields and the surrounding landscape during different farming seasons. 


\section{References}

Al-Dobai S, Reitz S, Sivinski J. 2012. Tachinidae (Diptera) associated with flowering plants: Estimating floral attractiveness. Biological Control 61(3): 230-239.

Altieri M. 2002. Agroecology: The science of natural resource management for poor farmers in marginal environments. Agriculture, Ecosystems, and Environment 93(1-3): 124.

Andow D. 1991. Vegetational diversity and Arthropod population response. Annual Review of Entomology 36: 561-586.

Barlow J, Jardner T, Peres C, Sodhi N. 2010. A multi-region assessment of tropical forest biodiversity in a human-modified world. Biological Conservation 143(10): 2293-2300.

Balvanera P, Daily G, Ehrlich P, Ricketts T, Bailey S, Kark S, Kremen C, Pereira G. 2001. Conserving biodiversity and ecosystem services. Science 291(5511): 2047-2047.

Barona E, Ramankutty N, Hyman G, Coomes O. 2010. The role of pasture and soybean in deforestation of the Brazilian Amazon. Enviro Research Letters 5(2).

Boody G, Vondracek D, Krinke A, Westra J, Zimmerman J, Welle P. 2005. Multifunctional agriculture in the United States. BioScience 55(1): 27-38.

Brodt S, Feenstra G, Kozloff R, Klonsky K, Tourte L. 2006. Farmer-community connections and the future of ecological agriculture in California. Agriculture and Human Values 23(1): 75-88.

Bunn D, Mummert A, Hoshovsky M, Gilardi K, Shanks S. 2005. California wildlife: Conservation challenges. California Department of Fish and Game: 197-234.

Butler S, Vickery J, Norris K. 2007. Farmland biodiversity and the footprint of agriculture. Science 315(5810): 381-384.

California Department of Fish and Game. 2006. California Wildlife Action Plan.

Chapin III F, Zavaleta E, Eviner V, Naylor R, Vitousek P, Reynolds H, Hooper D, Lavorel S, Sala O, Hobbie S, et al. 2000. Consequences of changing biodiversity. Nature 405(6783): 234-242.

DeFries R, Jonathan F, Asner G. 2004. Land-use choices: Balancing human needs and ecosystem functions. Frontiers in Ecology and the Environment 2(5): 249-257. 
Donald P, Evans A. 2006. Habitat connectivity and matrix restoration: The wider implications of agri-environment schemes. Appl Ecology 43(2): 209-218.

Duelli P, Studer M, Marchand I, Jakob S. 1990. Population movements of arthropods between natural and cultivated areas. Biological Conservation 54(3): 193-207.

Dyre L, Gentry G. 1999. Predicting natural-enemy responses to herbivores in natural and managed systems. Ecological Applications 9(2): 402-408.

Fearnside P. 2008. The roles and movements of actors in the deforestation of Brazilian Amazonia. Ecology and Society 13(1).

Foley J, DeFries R, Asner G, Barford C, Bonana G, Carpenter S, Chapin F, Coe M, Daily G, Gibbs H, et al. 2005. Global consequences of land use. Science 309(5734): 570-574.

Gardner T, Barlow J, Sodhi N, Peres C. 2010. A multi-region assessment of tropical forests biodiversity in a human-modified world. Biological Conservation 143(10): 22932300 .

Goldman M. 2007. How “Water for All!” policy became hegemonic: The power of the World Bank and its transnational policy networks. Science Direct 38(5): 786-800.

Green R, Cornell S, Scharlemann J, Balmford A. 2005. Farming and the fate of wild nature. Science 307(5709): 550-554.

Hility J, Brooks C, Heaton E, Merenlender A. 2006. Forecasting the effect of land-use change on native and non-native mammalian predator distributions. Biodiversity and Conservation 15(9): 2853-2871.

Jackson W. 2002. Natural systems agriculture: A truly radical alternative. Agriculture, Ecosystems, and Environment 88(2): 111-117.

Kegley S, Neumeister L, Martin T. 1999. Disrupting the balance: Ecological impacts of pesticides in California. (Pesticide Action Network)

Khan S, Hannjra M. 2009. Footprints of water and energy inputs in food productionGlobal perspectives. Food Policy 34(2): 130-140.

Kim J, Williams N, Kremen C. 2006. Effects of cultivation and proximity to natural habitat on ground-nesting native bees in California sunflower fields. Journal of the Kansas Entomological Society 79(4): 309-320. 
Kruess A, Tscharntke T. 2000. Species richness and parasitism in a fragmented landscape: Experiments and field studies with insects on Vicia sepium. Oecologia 122(1): 129-137.

Letourneau D, Bothwell S. 2008. Comparison of organic and conventional farms: Challenging ecologists to make biodiversity functional. Frontiers in Ecology and the Environment 6(8): 430-438.

Letourneau D, Jedlicka J, Bothwell S, Moreno C. 2009. Effects of natural enemy biodiversity on the suppression of arthropod herbivores in terrestrial ecosystems. Annual Review of Ecological Evolution 40: 573-592.

Letourneau DK, Armbrecht I, Rivera BS, Lerma JM, Carmona EJ, Daza MC, Escobar S, Galindo V, Gutiérrez C, López SD, et al. 2011. Does plant diversity benefit agroecosystems? A synthetic review. Ecological Applications 21(1): 9-21.

Letourneau D, Bothwell A, Stireman III J. 2012. Perennial habitat fragments, parasitoid diversity and parasitism in ephemeral crops. Applied Ecology 49(6): 1405-1416.

Lowrance R, Hendrix P, Odum E. 1986. A hierarchical approach to sustainable agriculture. American Journal of Alternative Agriculture 1(4): 169-173.

Matson P, Parton W, Power A, Swift M. 1997. Agricultural intensification and ecosystem properties. Science 227(5325): 504-509.

Moonen A, Bárberi P. 2008. Functional biodiversity: An agroecosystem approach. Agriculture, Ecosystems and Environment 127(1-2): 7-21.

Nepstad D, Stickler C, Oriana A. 2006. Globalization of the Amazon soy and beef industries: Opportunities for conservation. Conservation Biology 20(6): 1595-1603.

Norris K, Asase A, Collen B, Gockowksi J, Mason J, Phalan B, Wade A. 2010. Biodiversity in a forest-agriculture mosaic - the changing face of West African rainforests. Biological Conservation 143(10): 2341-2350.

Palmer M, Bernhardt E, Chornesky E, Collins S, Dobson A, Duke C, Gold B, Jacobson R, Kingsland S, Kranz R, et al. 2004. Ecology for a crowded planet. Science 304(5675): 1251-1252.

Perfecto I, Vandermeer, J. 2008. Biodiversity conservation in tropical agroecosystems: A new conservation paradigm. Annals of the New York Academy of Sciences 1134: 173200. 
Pimentel D, Stachow U, Takacs D, Brubaker W, Dumas A, Meaney J, O’Neil J, Onsi E, Corzilius D. 1992. Conserving biological diversity in agricultural/forestry systems.

Science 42(4): 354-362.

Pimentel D, Hepperley P, Hanson J, Hanson D, Seidel R. 2005. Environmental, energetic, and economic comparisons of organic and conventional farming systems. Bioscience 55(7): 573-582.

Ray D, Ugarte D, Tiller K. 2003. Rethinking US agricultural policy: Changing course to secure farmer livelihoods worldwide. Agricultural Policy Analysis Center.

Rudel T, DeFries R, Asner G, Laurence W. 2009. Changing drivers of deforestation and new opportunities for conservation. Conservation Biology 23(6): 1396-1405.

Robertson G, Broome E, Chornesky J, Frankenberger P, Johnson P, Lipson M, Miranowski J, Owens E, Pimentel D, Thrupp L. 2004. Rethinking the vision for environmental research in US agriculture. BioScience 54(1): 61-65.

Robertson G, Swinton S. 2005. Reconciling agricultural productivity and environmental integrity: A grand challenge for agriculture. Frontiers in Ecology and the Environment 3(1): 38-46.

Root R. 1973.Organization of a plant-arthropod association in simple and diverse habitats: The fauna of collards (Brassica Oleracea). Ecological Monographs 34(1): 95116.

Sajjad A, Saeed S. 2010. Floral host plant range of Syrphid flies (Syrphidae: Diptera) under natural conditions in southern Punjab, Pakistan. Pakistan Journal of Botany 42(2): 1187-1200.

Stuart D, Shennan C, Brown M. 2006. Food safety versus environmental protection on the Central California Coast: Exploring the science behind an apparent conflict. Research Briefs, Center for Agroecology and Sustainable Food Systems, UC Santa Cruz.

Stuart D. 2009. Constrained choice and ethical dilemmas in land management: Environmental quality and food safety in California agriculture. Journal of Agricultural and Enviro Ethics 22(1): 53-71.

Thrupp L. 2000. Linking agricultural biodiversity and food security: The valuable role of agrobiodiversity for sustainable agriculture. International Affairs 76(2): 265-281.

Tilman D. 1999. Global environmental impacts of agricultural expansion: The need for sustainable and efficient practices. Proc. Natl Acad Science 96(11): 5595-6000. 
Tilman D. 2001. Forecasting agriculturally driven global environmental change. Science 292(5515): 281.

Tilman D, Cassman K, Matson P, Naylor R, Polasky S. 2002. Agricultural sustainability and intensive production practices. Nature 418(6898): 671-677.

Tooker J, Hauser M, Hanks L. 2006. Floral host plants of Syrphidae and Tachinidae of Central Illinois. Annals of the Entomological Society of America 99(1): 96-112.

Tscharntke T, Bommarco R, Clough Y, Crist T, Klejin D, Rand T, Tylianakis J, Nouhuys S, Vidal S. 2007. Conservation biological control and enemy diversity on a landscape scale. Biological Control 43(3): 294-309.

Tscharntke T, Brandl R. 2004. Plant-insect interactions in fragmented landscapes. Annual Review of Entomology 49: 505-530.

Tscharntke T, Klein A, Kruess A, Steffan-Dewenter I, Thies C. 2005. Landscape perspectives on agricultural intensification and biodiversity - ecosystem service management. Ecology Letters 8(8): 857-874.

Tsegaye B. 1997. The significance of biodiversity for sustaining agriculture and the role of women in the traditional sector: The Ethiopian experience. Agriculture, Ecosystems, and Environment 62(2-3): 215-227.

United States Census Bureau 2011. Population distribution and change: 2000-2010.

United States Department of Agriculture. 2011. California agricultural statistics: 2010 crop year. Washington, DC: Author. $102 \mathrm{p}$. 